Universidade de Brasília

Faculdade de Economia, Administração, Contabilidade e Ciências da Informação e Documentação

\author{
DEPARTAMENTO DE ADMINISTRAÇÃO
}

TRABALHO DE CONCLUSÃO DE CURSO

\title{
DEMANDAS DE EDUCAÇÃO FINANCEIRA PESSOAL NO ENSINO MÉDIO PÚBLICO E PRIVADO DO DISTRITO FEDERAL
}

\section{Christopher Aviz}




\section{DEMANDAS DE EDUCAÇÃO FINANCEIRA PESSOAL NO ENSINO MÉDIO PÚBLICO E PRIVADO DO DISTRITO FEDERAL}

\section{Christopher Aviz}

Professor Orientador:

\section{Professor Doutor José Márcio Carvalho}

"Trabalho apresentado em cumprimento às exigências acadêmicas parciais da disciplina Estágio Supervisionado em administração para a obtenção do grau de Administrador" 
Universidade de Brasília

Faculdade de Economia, Administração, Contabilidade e Ciências da Informação e Documentação

DEPARTAMENTO DE ADMINISTRAÇÃO

\section{DEMANDAS DE EDUCAÇÃO FINANCEIRA PESSOAL NO ENSINO MÉDIO PÚBLICO E PRIVADO DO DISTRITO FEDERAL}

A Comissão Examinadora, abaixo identificada, aprova o Trabalho de Conclusão do Curso de Administração da Universidade de Brasília do aluno

\section{Christopher Aviz}

José Márcio Carvalho, Doutor

Professor-Orientador

Luciene Braz Ferreira

Professor-Examinador
Olinda Maria Gomes Lesses

Professor-Examinador 
Dedicatória

Às pessoas amadas das quais da companhia ausentei-me para atingir este objetivo. 


\section{Agradecimentos}

Primeiramente a Deus, por ser a razão da minha existência.

À minha família o exemplo de amor, carinho e união.

A todas as pessoas que contribuíram em minha experiência de vida, ensinando-me a aprender com humildade, a querer ser uma pessoa melhor e a amar. 


\section{Epígrafe}

“Conhecer é tarefa de sujeitos, não de objetos. E é como sujeito e somente enquanto sujeito, que o homem pode realmente conhecer." 


\section{RESUMO}

Complexas mudanças na estrutura econômico-social alteraram a forma como o indivíduo se relaciona com o dinheiro. A fim de que neste contexto seja possível manter uma vida financeira saudável, contribuindo para o bem estar da sociedade, a educação financeira pessoal se posiciona como o conjunto de conhecimentos que auxilia as pessoas a gerenciar melhor o seu dinheiro. Tais informações não são difundidas durante a formação básica do cidadão brasileiro. Esta pesquisa foi desenvolvida com o objetivo de investigar e comparar percepções sobre a relevância da educação financeira pessoal em escolas públicas e privadas do Distrito Federal. O tema é incipiente em no Brasil quando se comparado com países desenvolvidos, como Estados Unidos e Inglaterra. Devido a esta realidade, buscou-se fazer uma pesquisa exploratória, envolvendo professores e coordenadores, e descritiva, ao tratar percepções de estudantes. Foram coletadas informações por meio da aplicação de questionários para os estudantes da terceira série do Ensino Médio e da realização de entrevistas com professores e coordenadores de escolas do mesmo nível de ensino. Obteve-se como resultado a atribuição de grande relevância ao ensino da educação financeira pessoal, tanto por parte dos estudantes como dos coordenadores e professores. Grande parte dos alunos nunca teve uma aula sobre o tema e, mesmo assim, considera que a escola seria o ambiente adequado para 0 ensino de finanças pessoais. Os resultados descrevem primeiramente o perfil dos estudantes. Em seguida, são descritos os conteúdos, em ordem de importância segundo a percepção dos alunos e também os conteúdos que os alunos afirmam já possuir conhecimento suficiente para tomar decisões. Compara-se a estes dados a forma como os alunos afirmam se comportar quando tomam decisões que envolvem dinheiro e também as percepções de coordenadores e professores sobre o tema. 


\section{SUMÁRIO}

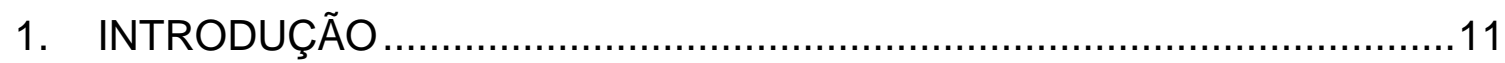

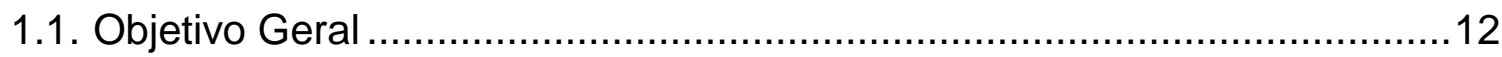

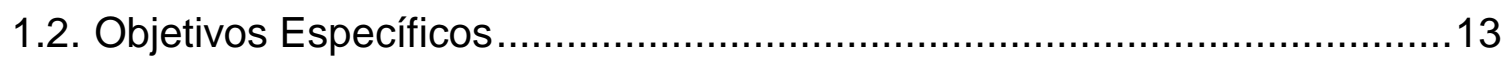

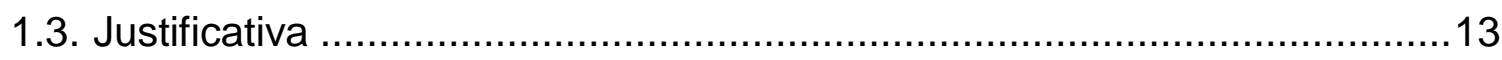

1.4. Métodos e Técnicas de Pesquisa ..........................................................

1.5. Estrutura da Monografia......................................................................

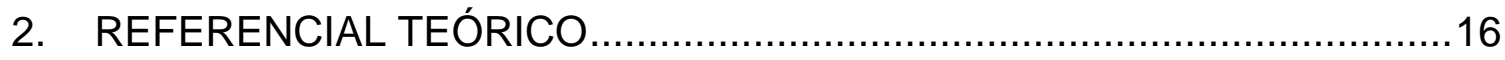

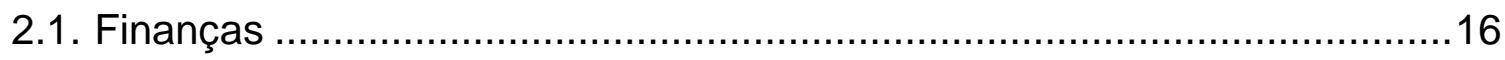

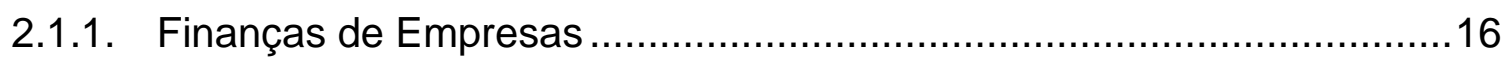

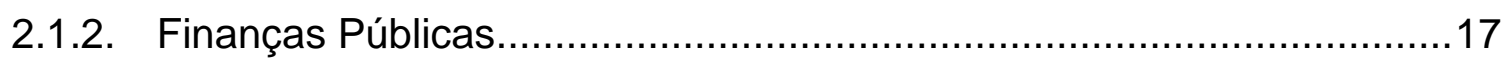

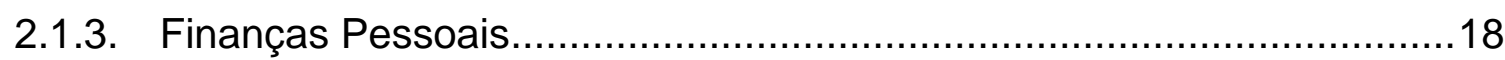

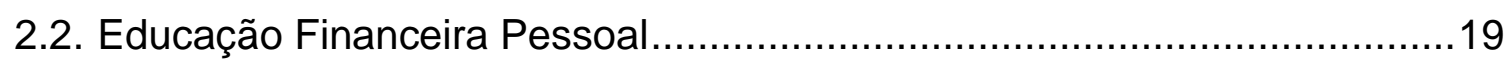

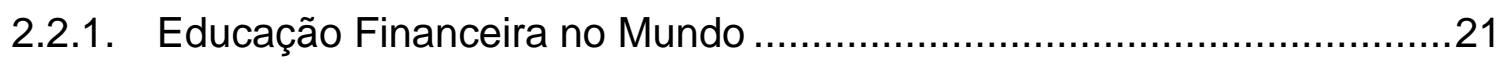

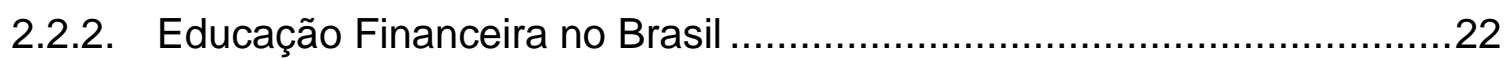

2.2.3. Informações sobre Educação Financeira Disponíveis à População ......23

2.3. Educação e o Ensino de Finanças Pessoais .............................................24

2.3.1. Matemática Financeira no Ensino Médio............................................25

2.3.2. Comentários sobre Educação Financeira Pessoal no Ensino Médio.....26

3. MÉTODOS E TÉCNICAS DE PESQUISA …...........................................27

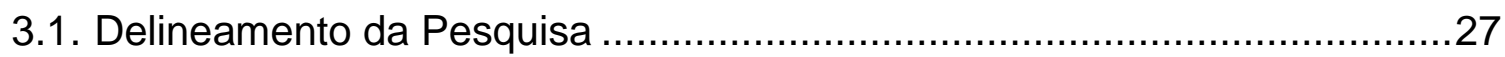

3.2. Descrição das Variáveis de Pesquisa ...................................................27

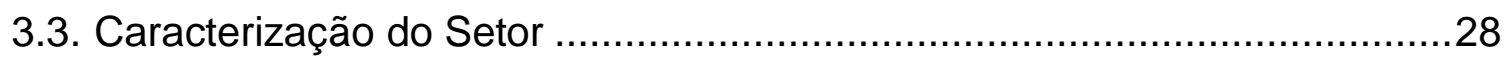

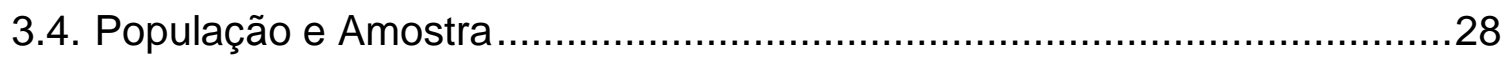

3.5. Procedimentos e Instrumentos Utilizados na Coleta e Análise dos Dados.29

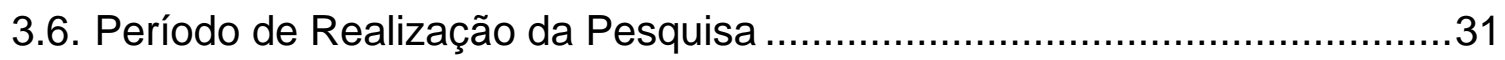

3.7. Comentários Sobre o Processo de Coleta de Dados.................................32

4. APRESENTAÇÃO E ANÁLISE DOS RESULTADOS DA PESQUISA .........33

4.1. Perfil dos Estudantes da Terceira Série do Ensino Médio ..........................33

4.2. Relevância do Ensino da Educação Financeira Pessoal ............................35

4.3. Importância dos Conteúdos de Educação Financeira Pessoal ...................37

4.4. Domínio de Conteúdos de Educação Financeira Pessoal ...........................39

4.5. Conteúdos de Educação Financeira Pessoal Prioritários ...........................42

4.6. Comportamentos que Indicam Gestão Adequada dos Recursos Financeiros Pessoais. 
4.7. Comportamentos que Indicam Gestão Inadequada dos Recursos Financeiros Pessoais .45

4.8. Comportamentos que Indicam Estratégias de Longo Prazo para as Finanças Pessoais .46

4.9. Percepção de Professores e Coordenadores sobre Educação Financeira

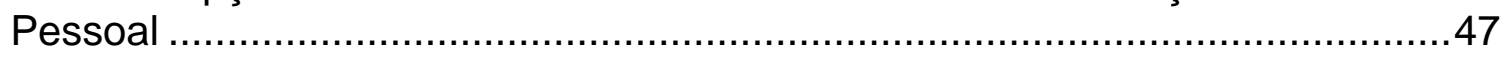

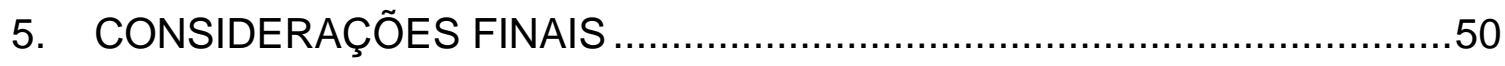

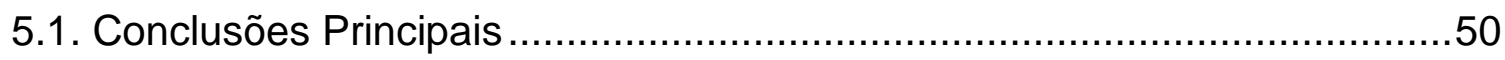

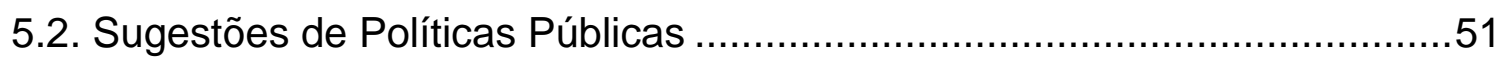

5.3. Sugestões de Novas Pesquisas .........................................................

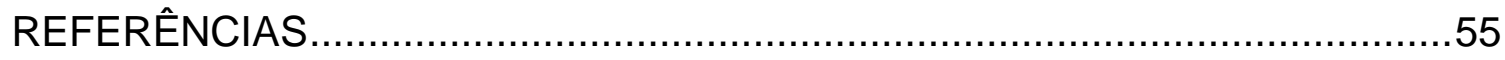

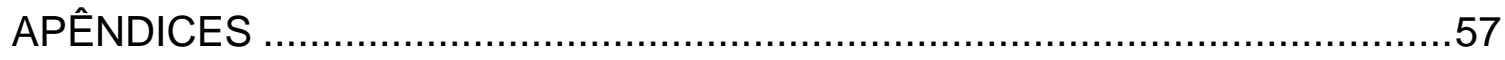




\section{LISTA DE ILUSTRAÇÕES}

Figura 1 - Percepção sobre a Importância da obtenção de Informações Voltadas à Educação Financeira Pessoal 35

Figura 2 - Porcentagem de Alunos que Tiveram Alguma Aula Cujo Conteúdo Ministrado Estava Relacionado à Educação Financeira Pessoal.......................36

Figura 3 - Porcentagem de Alunos que Consideram que a Educação Financeira Pessoal Deveria Ser Ensinada na Escola .......................................................37

Figura 4 - Porcentagem do Número de Conteúdos Mencionados como Dominados pelos Estudantes. 40

Figura 5 - Porcentagem de Alunos que Afirmam ter Domínio sobre Cada Conteúdo de Educação Financeira Pessoal. 


\section{LISTA DE TABELAS}

Tabela 1 - Freqüência e Porcentagem de Alunos Classificados de Acordo com a Renda Familiar Mensal 34 Tabela 2 - Assuntos de Educação Financeira Pessoal em Ordem de Importância na Percepção de Alunos da Terceira Série do Ensino Médio ...................................38

Tabela 3 - Conteúdos em Ordem de Prioridade ..................................................42

Tabela 4 - Porcentagem de Estudantes que Afirmam ter Comportamentos que Indicam Gestão Adequada dos Recursos Financeiros Pessoais .......................44

Tabela 5 - Porcentagem de Estudantes que Afirmam ter Comportamentos que Indicam Gestão Inadequada dos Recursos Financeiros Pessoais ....................45

Tabela 6 - Porcentagem de que Afirmam ter Comportamentos que Indicam Gestão Inadequada dos Recursos Financeiros Pessoais .........................................46 


\section{INTRODUÇÃO}

Estudos nos Estados Unidos e no Reino Unido apontam a crescente relevância do ensino da educação financeira na formação básica de seus cidadãos a fim de prepará-los para gerir suas finanças de forma equilibrada e lidar com a complexidade do cenário econômico atual. Mudanças econômico-sociais criaram a necessidade da tomada de decisões financeiras cada vez mais freqüentes e que impactam a vida das pessoas a curto, médio e longo prazo.

No Brasil, vê-se vagarosamente o surgimento de iniciativas para a criação de um cenário que possibilite maior difusão de informações financeiras para a população. A alfabetização financeira é um processo de educação e de responsabilidade de pais, escolas, governo e instituições privadas, envolvendo vários atores sociais.

Existe ainda uma herança cultural na forma de pensar no assunto "dinheiro" surgido do momento de descontrole inflacionário que permaneceu até o início da década de 90. A preocupação em manter o poder de compra incentivava as pessoas a consumir baseadas em uma análise de curto prazo. Hoje, as relações com o dinheiro, estão mais complexas; noções de administração, economia, finanças, comércio e impostos são fundamentais para a tomada de decisão e gestão financeira de um indivíduo de forma saudável tanto no curto como no médio e longo prazo. Percebe-se, neste ponto, a falta de capacitação financeira para que o indivíduo seja capaz de tomar decisões de consumo, poupança e investimentos que contribuam para o seu bem-estar social.

Portanto, faz-se necessário avaliar primeiramente as informações que são disponibilizadas atualmente para os consumidores sobre educação financeira pessoal e avaliar a demanda por informações sobre o tema, a fim de que seja suprida alguma necessidade por informações de educação financeira pessoal na sociedade.

É importante observar que a falta de informações relacionadas a educação financeira pessoal acarreta uma deficiência na formação do cidadão brasileiro, uma vez que esta informação é vital para o bem estar das pessoas, auxiliando-as ao tomar decisões que terão impacto em suas vidas. São decisões de consumo, poupança e investimentos de recursos, tomadas diariamente sem que 
uma análise crítica sobre os benefícios destes produtos ou serviços contratados seja realizada, o que demonstra falta de preparo das pessoas em relação ao assunto.

O desconhecimento de informações financeiras por parte do cidadão permite que pessoas ou empresas mais informadas possam tirar proveito desta situação ao oferecer um produto ou serviço que muitas vezes não é o ideal para o consumidor. Ao ter acesso a informações financeiras, a população aumenta suas possibilidades de escolha frente a quantidade de recursos financeiros disponíveis que, para serem utilizados, é preciso instrução.

Desta forma, percebe-se a existência de uma falha na formação do cidadão, que possibilita o comprometimento futuro de suas finanças e pode, até mesmo, levá-lo a um caminho sem volta. O Brasil tem ofertado uma quantidade cada vez maior de crédito e observa-se alto grau de endividamento da população brasileira. A renda dos brasileiros está cada vez mais comprometida com dívidas de bens comprados através de financiamentos e pouca parte é destinada para rendimento em poupança, o que poderia garantir ao consumidor, além do juro gerado, a possibilidade de barganha no pagamento à vista do produto desejado. No entanto, o despreparo para gerir recursos financeiros pessoais e a falta de planejamento financeiro resulta em dívidas sobre dívidas e grande quantidade de cartões de crédito faz-se necessário para sustentar este ciclo.

Outros problemas ainda somam-se a estes, como por exemplo, a atual necessidade de se pensar na aposentadoria, uma vez que não se tem mais a estrutura do Estado como paternalista, tendo cada indivíduo que tomar para si a responsabilidade de poupar recursos para gozar no futuro de uma velhice mais tranqüila.

\subsection{Objetivo Geral}

Investigar e comparar percepções sobre a relevância da educação financeira pessoal no Ensino Médio em escolas públicas e privadas do Distrito Federal. 


\subsection{Objetivos Específicos}

Avaliar a importância do ensino da educação financeira em escolas públicas e privadas do Distrito Federal.

Estimar o domínio da educação financeira por alunos de escolas públicas e privadas do Distrito Federal.

Identificar os conteúdos percebidos como prioritários por alunos e professores de escolas públicas e privadas do Distrito Federal.

\subsection{Justificativa}

Ao verificar a relevância do ensino da educação financeira pessoal e identificar os conteúdos vistos como prioritários para a formação do cidadão brasileiro na opinião de alunos, professores e especialistas, a pesquisa busca evidenciar o tema. Também ressalta soluções em termos de conteúdo a fim de que a população, ao ter acesso a estas informações, tenha capacidade de análise para tomar decisões que impactem direta ou indiretamente na gestão de suas finanças. $O$ impacto desta mudança poderá ser percebido no bem estar da sociedade.

O desenvolvimento de ações para corrigir uma possível falha em relação ao ensino dos conteúdos sobre o tema requer a observação da existência de uma lacuna na formação básica do cidadão, no que tange às demandas por informações de educação financeira pessoal, e a oferta existente no ensino.

A sociedade enfrenta problemas gerados pela falta de instrução financeira da população. Oferecer uma resposta quanto ao conteúdo prioritário para a efetiva formação de adultos capazes de tomar decisões financeiras assertivas contribui para a tomada de decisão consciente frente a complexidade dos impactos gerados por suas decisões.

A partir desta pesquisa, o meio acadêmico obtém mais informações para realizar futuros questionamentos e tem em mãos dados para reforçar considerações a respeito do assunto, auxiliando no processo de construção de conhecimento que levará a uma mudança na forma de pensar o tema. 
Sendo assim, fez-se fundamental a realização desta pesquisa a fim de coletar informações de alunos do Ensino Médio, coordenadores pedagógicos e professores que possibilitassem entender melhor a relevância da educação financeira pessoal para a formação dos cidadãos brasileiros e para a sociedade.

\subsection{Métodos e Técnicas de Pesquisa}

Pela pouca disponibilidade de material científico relacionado ao tema, houve a necessidade de se investigar e descobrir fundamentos para esta pesquisa, sendo esta parte caracterizada como exploratória. Outra parte, caracterizada como descritiva, foi fundamental para a coleta de percepções a respeito de educação financeira pessoal em escolas de formação básica.

Foram aplicados questionários a estudantes da terceira série do Ensino Médio de escolas públicas e privadas do Distrito Federal e foram realizadas entrevistas com professores e coordenadores pedagógicos dos mesmos colégios onde estudam os alunos que responderam aos questionários.

O questionário respondido pelos alunos teve como pretensão coletar percepções sobre a relevância de se obter informações sobre educação financeira pessoal, coletar medidas em relação a interesse e domínio de conteúdos de educação financeira pessoal.

$\mathrm{Na}$ entrevista com os coordenadores pedagógicos e professores buscouse obter a opinião destes sobre o tema na formação do cidadão brasileiro e verificar a importância dada pelas escolas para a educação financeira pessoal.

\subsection{Estrutura da Monografia}

O trabalho está dividido em cinco partes: introdução, referencial teórico, métodos e técnicas de pesquisa, análise dos dados coletados e considerações finais.

$\mathrm{Na}$ introdução há a contextualização do assunto e delimitação do tema, assim como a descrição do problema de pesquisa a ser estudado e seus objetivos. 
No referencial teórico são abordados tópicos necessários para o entendimento do assunto, que também servem como base para análise dos dados. São expostas considerações de autores a respeito de temas relevantes para a realização da pesquisa. Primeiramente se passa uma idéia ampla sobre a área de finanças, dividindo-a em finanças de empresas, finanças públicas e finanças pessoais. Depois é feito um levantamento mais específico em educação financeira pessoal, considerando a percepção dos principais autores sobre o tema. Outro tópico abordado é a educação e o ensino de finanças pessoais. Discute-se ainda os conteúdos que são ministrados atualmente quando se trata matemática financeira dentro de sala de aula para alunos do Ensino Médio.

Nos métodos e técnicas de pesquisa se discorre sobre o tipo de pesquisa, a delimitação da população e da amostra, os instrumentos e procedimentos.

$\mathrm{Na}$ análise dos dados a preocupação inicial é em informar o perfil dos estudantes. Em seguida, busca-se atingir os objetivos da pesquisa, discorrendo sobre as informações geradas pelo questionário e pelas entrevistas.

Por fim, são realizadas as considerações finais onde se dá o desfecho da pesquisa e são feitas sugestões para as escolas, assim como sugestões de políticas públicas e de futuras pesquisas sobre o tema, além da realização da avaliação geral da pesquisa. 


\section{REFERENCIAL TEÓRICO}

Este capítulo está dividido em quatro partes, sendo que a primeira trata de finanças, envolvendo as finanças de empresas, as finanças públicas e as finanças pessoais; a segunda aborda a educação financeira pessoal e suas percepções em outros países e também no Brasil; a terceira parte analisa a educação e o ensino da educação financeira pessoal.

\subsection{Finanças}

As finanças são definidas como a arte e a ciência de administrar valores. Em geral, todos os indivíduos e empresas recebem ou capitalizam e gastam ou investem dinheiro. As finanças tratam com o processo, as instituições, os mercados e os instrumentos envolvidos na transferência de dinheiro entre as pessoas, os negócios e os governos (GITMAN, 2001).

Observa-se a aplicação da teoria financeira desde níveis macros até níveis micros na sociedade. Em empresas privadas a aplicação da teoria é de fundamental importância para a tomada de decisões que envolvam a empresa como um todo. Em empresas públicas os gestores lidam com o recebimento e gasto de recursos que impactam na sociedade. Com maior facilidade observa-se também as finanças na vida de famílias e indivíduos, onde estes gerem suas finanças a todo momento nas decisões de consumo.

Portanto, existe grande abrangência do estudo da ciência das finanças. Em várias áreas observa-se a administração de recursos financeiros para um objetivo específico. Descrevê-las é fundamental para que se tenha um melhor entendimento das inter-relações que envolvem as finanças de empresas, finanças públicas e finanças pessoais.

\subsubsection{Finanças de Empresas}

As empresas gerenciam, dentre uma grande quantidade de recursos, os recursos financeiros. Estes têm um significado muito importante para as organizações, pois sua análise determina uma série de decisões financeiras 
fundamentais para o andamento das suas atividades. É a área financeira da empresa que irá indicar se a organização está atingindo seu grande objetivo: maximização da riqueza do acionista (BRIGHAM; HOUSTON, 1999).

Segundo Bitencourt (2005 apud Bodie e Merton, 1999), existem três decisões financeiras básicas, que são: decisões de planejamento estratégico, decisões de orçamento de capital e decisões de capital de giro, que fazem uso de relatórios contábeis, como: demonstração do resultado do exercício, balanço patrimonial, fluxo de caixa e demonstração da mutação do patrimônio líquido.

Portanto, a área financeira de uma empresa envolve conceitos de outras grandes áreas: administração, economia e contabilidade. É por meio de conceitos econômicos que a área financeira poderá estimar, por exemplo, a quantidade do produto a ser comercializado. Num outro ponto, utiliza-se do desenvolvimento de dados pela área contábil que indicam o posicionamento financeiro da empresa e os devidos tributos a serem pagos.

Para Cherry (1977, p. 18), "as finanças de empresas se referem à administração do dinheiro e das reivindicações monetárias dentro da firma". De uma forma geral, as empresas utilizam informações financeiras para tomar decisões, partindo da análise do seu posicionamento atual e visando um posicionamento futuro a partir da forma como administram seus recursos financeiros.

\subsubsection{Finanças Públicas}

Normalmente os órgãos governamentais se interessam por outro motivo que não o financeiro, mas o de satisfazer as necessidades da população. As finanças públicas lidam como uma forma de gerir recursos financeiros públicos para financiar projetos e oferecer serviços para a sociedade, como uma troca.

As finanças públicas estudam a administração e as reivindicações monetárias dentro de unidades governamentais. Esta área interessa-se pelos problemas resultantes do poder governamental de tributar e pelas limitações legais sobre os meios, pelos quais as unidades públicas podem levantar e utilizar fundos (CHERRY, 1977, p. 17). 
O estudo desta área de finanças envolve o planejamento da receita gerada através da arrecadação para o Estado e sua destinação, ou gasto, dos valores recebidos por meio de tributos para o bem da sociedade.

A análise dos indicadores financeiros fornece para o tomador de decisões subsídios para atingir os objetivos da gestão pública, como por exemplo, atingir altos níveis de renda e de emprego. As decisões financeiras públicas estão relacionadas com a forma de gerir do governo, suas prioridades e suas demandas.

\subsubsection{Finanças Pessoais}

A área de finanças pessoais trata da forma como um indivíduo ou uma família administra sua renda. Diariamente decisões financeiras são tomadas e estas terão impacto na vida pessoal dos indivíduos.

Para Martins (2004, p. 37) "a incapacidade de ler e entender demonstrações financeiras é responsável por fracassos e por erros que podem ser fatais". Ao estudar as finanças pessoais, aprende-se a aplicar conceitos e técnicas fundamentais para a existência de uma organização pública ou privada na gestão da renda de uma família.

As demonstrações financeiras, que segundo Martins (2004) são de fundamental importância para as finanças de uma pessoa são: balanço patrimonial, demonstração da renda e fluxo de caixa. A partir das demonstrações pode-se gerar informações que auxiliam a tomada de decisão para uma família.

O balanço patrimonial é um retrato da situação financeira de um indivíduo ou família. Nela constam ativos (bens e direitos), passivos (dívidas e obrigações a cumprir) e patrimônio líquido (saldo). Ressalta-se aqui a importância do entendimento de ativo e passivo, visto que dependendo do resultado gerado pelo mesmo bem, pode ser classificado como passivo ou ativo. A análise do balanço demonstra onde estão os recursos da família, possibilitando dizer se o investimento realizado contribuiu ou não para sua saúde financeira (MARTINS, 2004).

Pela elaboração da demonstração da renda verificam-se todos os ganhos e os gastos realizados durante um período, identificando o saldo positivo ou negativo ao final do período. A análise da demonstração da renda permite identificar para 
onde está indo a renda da família e onde são realizadas as maiores despesas (MARTINS, 2004).

O fluxo de caixa permite que se entenda o fluxo de recursos que entram e saem da conta de uma pessoa, auxiliando no planejamento financeiro de curto e médio prazo, informando da necessidade de capital para quitar uma dívida ou da sobra deste para realizar algum investimento. Auxiliam nas decisões quanto a empréstimos e custo real do bem (MARTINS, 2004).

Mesmo com conhecimentos sobre "como fazer" trazidos pelas noções de contabilidade, existe ainda a necessidade por informações que possibilitem saber "o quê fazer". Para Cerbasi (2004, p. 90) "muitas das decisões que tomamos em relação a dinheiro decorrem de hábitos, nem sempre saudáveis, que imitamos da maioria das pessoas que conhecemos". Isto indica o quanto deve-se observar os comportamentos com relação aos hábitos de consumo, investimento, poupança e gerenciamento de gastos. Pode acontecer a repetição de um padrão de comportamento capaz de levar o indivíduo à riqueza ou à pobreza.

A poupança pode produzir uma segurança necessária para a vida do indivíduo, assim como os investimentos de uma pessoa podem ser mais precisos e planejados de acordo com as suas necessidades de curto e longo prazo, resultando em ganhos maiores para a vida financeira das pessoas. Poupar exige o adiamento do consumo presente, visando o consumo de algo maior no futuro. Dois objetivos motivam as pessoas a poupar, sendo um deles a possibilidade de consumir mais em certo tempo e o outro as adversidades causadas pelo envelhecimento e a queda de produtividade para a geração de receitas suficientes para arcar com as despesas (HALFELD, 2004).

\subsection{Educação Financeira Pessoal}

A educação financeira mostrou-se relevante aos consumidores desde 0 seu surgimento a fim de auxiliá-los a administrar seus rendimentos, a poupar e a investir, evitando que se tornem vítimas de golpes. Entretanto, esta importância tem se tornado maior nos últimos anos, em decorrência da grande aceleração vista nos mercados financeiros e de mudanças demográficas, econômicas e políticas (OCDE, 2004). 
Desde o surgimento do sistema capitalista as pessoas tiveram a necessidade de se adaptar ao novo conceito de dinheiro e suas variáveis mais complexas comparadas aos sistemas anteriores. As novas relações de troca, domínio e poder fundamentaram as bases econômico-sociais vigentes ainda nos dias de hoje (MATTA,2007).

A evolução do sistema criou a necessidade de informações que ajudassem as pessoas a gerir de forma adequada seus bens e rendimentos, uma vez que o capitalismo defendia a propriedade privada, a livre exploração dos meios de produção e baseava-se na lei da oferta e demanda. O direito ao lucro abriu uma série de oportunidades mercadológicas, oferecendo-se assim uma gama de novos produtos e serviços, também financeiros. Surgem, neste momento, dificuldades de escolha, que vão além da decisão entre aquisição de serviços e produtos, incluindo: necessidades, desejos, planejamento financeiro e endividamento, que impactariam diretamente na vida das pessoas. A educação financeira surge como resposta para orientar a tomada de decisões, informando sobre os serviços financeiros ofertados, sobre necessidades e desejos de consumo, de necessidades de poupança, financiamentos e juros, investimentos e rendimentos. Pode ser entendida como "o conjunto de informações que auxilia as pessoas a lidarem com a sua renda, com a gestão do dinheiro, com gastos e empréstimos monetários, poupança e investimentos de curto e longo prazo" (MATTA, 2007, p.59).

A educação financeira também pode ser entendida como

\begin{abstract}
Um processo de transmissão de conhecimento que permite 0 desenvolvimento de habilidades nos indivíduos, para que eles possam tomar decisões fundamentadas e seguras, melhorando o gerenciamento de suas finanças pessoais. Quando aprimoram tais capacidades, os indivíduos tornam-se mais integrados à sociedade e mais atuantes no âmbito financeiro, ampliando o seu bem-estar (SAVOIA; SAITO e SANTANA, 2007, p. 2).
\end{abstract}

Para Matta (2007 apud GREENSPAN, 2005, p. 54) "devido ao extraordinário crescimento e progressos tecnológicos nos serviços financeiros, temse obtido muitos benefícios para os consumidores de créditos pessoais e de investimentos", o que, de certa forma, cria a necessidade de informações sobre estes produtos e serviços para a população orientar sobre suas vantagens e desvantagens. 
A difusão da educação financeira às pessoas impactaria na forma como estas poderiam aproveitar as oportunidades de produtos e serviços ofertados de uma forma consciente.

\subsubsection{Educação Financeira no Mundo}

Algumas organizações ao redor do mundo já identificaram certa demanda por educação financeira da população, principalmente aquelas que têm seu trabalho voltado para questão de qualidade de vida, satisfação e bem-estar econômico e social da população. Uma delas é a Organização das Nações Unidas - ONU, que em suas Orientações para a Proteção do Consumidor, atentam para os princípios que devem ser seguidos por governos dos países do mundo, onde destacam-se dois de extrema proximidade com a educação financeira, que são:

c) acesso dos consumidores à informação adequada que o habilite a tomar decisões conscientes conforme suas necessidades e desejos individuais e d) educação do consumidor, incluindo educação quanto aos impactos econômicos, sociais e no meio ambiente decorrente de suas escolhas. (MATTA, 2007 apud ONU, 2003, P. 2 - 3)

A difusão desta informação acarreta em uma série de vantagens, já percebidas principalmente por países desenvolvidos, onde se desperta a consciência dos cidadãos para tomar decisões que afetam não somente a sua vida, mas a do sistema financeiro como um todo, uma vez que milhões de pessoas não instruídas tomando decisões não sustentáveis para o sistema, haverá um impacto extremamente negativo na sociedade.

Em outros países, a difusão da educação financeira foi incentivada por diferentes atores sociais. No caso da Inglaterra, o incentivo para o ensino da educação financeira nas escolas foi gerado pelo Bank of England. Nos Estados Unidos, o Federal Reserve possui diversos programas voltados para públicos distintos, como professores, alunos e cidadãos (MATTA, 2007).

A Organização para Cooperação e Desenvolvimento Econômico (OCDE) desenvolveu o Financial Education Project, cujo objetivo principal era o estudo da educação financeira pessoal a fim de desenvolver programas para seus países membros. Foi observado que estes países possuíam políticas para difusão de 
informações sobre crédito, investimentos e instrumentos de seguro, mostrando também preocupação com a parte da população que é jovem (SAVOIA; SAITO e SANTANA, 2007 apud OCDE, 2004).

\subsubsection{Educação Financeira no Brasil}

Diversos países do mundo, dentre eles, Estados Unidos e países do Reino Unido, apontam para a necessidade de se difundir os conteúdos de educação financeira para a população a fim de alfabetizá-la e aumentar o seu nível de renda, sendo o foco desta difusão escolas de Ensino Médio e universidades. Em sua maioria, estes países são desenvolvidos e tratam de forma diferente o assunto dinheiro, porém, a necessidade por este tipo de informação é grande também em países em desenvolvimento (SAVOIA; SAITO; SANTANA, 2007).

No Brasil, as mudanças trazidas principalmente pela estabilização da economia e a queda da inflação alterou a forma como a população lida com seus recursos financeiros. A aceleração do crescimento da oferta de serviços bancários e o acesso facilitado a estes serviços para a população culminou em uma grande massa com acesso a crédito e financiamento, porém, sem instrução para usufruir de forma saudável destes serviços (MATTA, 2007).

A educação financeira pessoal "é fundamental na sociedade brasileira contemporânea, visto que influencia diretamente as decisões econômicas dos indivíduos e das famílias" (SAVOIA; SAITO; SANTANA, 2007, p.5).

O Brasil tem buscado uma solução para esta questão, principalmente pela iniciativa de desenvolvimento e divulgação de informações como o Código de Defesa do Consumidor, alertando a população para a legislação que rege as relações de compra e venda no país. Esta iniciativa envolve uma série de empresas públicas e privadas para a defesa do consumidor.

No entanto, segundo Savoia, Saito e Santana (2007, p. 5) "é evidente que no Brasil as autoridades não exercem a função de capacitar a população adequadamente para a tomada de decisões no âmbito financeiro". Não se percebe nenhuma iniciativa efetiva de difundir informações sobre educação financeira pessoal para a população. Uma das razões apontadas para este cenário é o 
desconhecimento da relevância da educação financeira por parte dos próprios governantes e da sociedade.

Muito pouco se encontra a respeito do assunto em termos de pesquisa no país. A área é bastante incipiente e caminha a passos curtos. Uma grande quantidade de estudiosos e instituições públicas e privadas começam a iniciar projetos que fomentam a alfabetização financeira no país, a fim de mudar este cenário.

\subsubsection{Informações sobre Educação Financeira Disponíveis à}

\section{População}

A Bolsa de Valores de São Paulo (BOVESPA) disponibiliza para a sociedade, através o Programa Educacional, criado em parceria com as suas corretoras de valores, conceitos sobre o tema educação financeira através de cursos e palestras. Este programa é voltado para qualquer indivíduo e difunde informações a respeito de hábitos de poupança, tipos de investimentos e planejamento de finanças pessoais, além de orientar sobre a importância destes conceitos para o desenvolvimento da economia do país (BOVESPA).

O Banco Central do Brasil (BACEN) desenvolveu o Programa de Educação Financeira (PEF) para orientar melhor as pessoas sobre a importância do planejamento financeiro e também para auxiliar os indivíduos a entender melhor o funcionamento da economia, assim como de seus agentes e instrumentos. O PEF atua em vários níveis para a divulgação de informações financeiras para a sociedade, contendo programas para o ensino Fundamental e Médio, momento importante para a formação adulta do indivíduo (BACEN).

A Centralização dos Serviços Bancários (SERASA) desenvolveu uma cartilha disponibilizada em seu site e denominada Guia SERASA de Informação ao Cidadão. Esta cartilha oferece informações que podem auxiliar o cidadão a gerir suas finanças de forma mais saudável. Assim como o SERASA, instituições financeiras tem tido interesse em informar seus clientes e até mesmo a sociedade como um todo sobre finanças pessoais para que estas pessoas possam aprender a gerenciar seus recursos, assumir suas dívidas e além disto, aprender a utilizar os serviços financeiros de acordo com as suas necessidades (SERASA). 


\subsection{Educação e o Ensino de Finanças Pessoais}

Os participantes no processo de educação financeira são as escolas, as empresas, o Governo, as instituições financeiras, e outros, como as organizações não-governamentais (HOLZMANN; MIRALLES, 2005 apud SAITO; SAVOIA; PETRONI, 2006, p.4).

Lucey e Giannangelo (2006, p. 270 apud MATTA, 2007, p. 63) afirmam que "se a criança desenvolve os moldes comportamentais e cognitivos antes e durante a escola elementar, a educação financeira deve ocorrer durante os primeiros estágios de desenvolvimento comportamental e cognitivo".

Uma pesquisa desenvolvida por Morton (2005) em alunos do ensino fundamental e médio dos Estados Unidos para verificar a eficácia da educação financeira nas escolas americanas apontou para um maior desenvolvimento cognitivo nos estudantes que tiveram acesso a informações financeiras. $O$ autor concluiu que "a adoção da educação econômica e educação de finanças pessoais devem ir além de serviços superficiais e deve tornar-se parte integral do currículo escolar das crianças e jovens do ensino fundamental e médio" (MORTON, 2005, p. 67 apud MATTA, 2007, p. 63).

Para Halfeld (2004, p. 19) a educação é "a grande ferramenta para a redução de desigualdades sociais", evidenciando a importância da educação para o crescimento financeiro de uma pessoa, uma sociedade e um país. É notória esta relação quando se analisa grandes nações que despertaram para o crescimento econômico a partir da educação, o que possibilitou o aumento da renda da sua população.

O sistema de ensino exige que uma criança passe nove anos no Ensino Fundamental mais três anos no Ensino Médio, onde após 12 anos conclui-se a formação básica do cidadão. Durante todos estes anos existe uma série de conteúdos que incentivam as crianças a aprenderem datas e nomes que futuramente terão pouca utilidade. Noções de comércio, economia, finanças ou impostos são muitas vezes ignorados, junto com o assunto "dinheiro", que todos um dia terão a necessidade de gerenciá-lo (HALFELD, 2004). 
Para Cerbasi (2004), ainda assim existe uma possibilidade de educar os filhos, que é dentro de casa. Por mais que a escola não instrua o aluno com relação a educação financeira pessoal, os pais devem compartilhar com os filhos decisões que envolvem dinheiro, como investimentos e planejamento para o futuro, explicando também as razões pelas quais aquelas decisões foram tomadas e levando o filho a refletir e aprender as variáveis que envolvem cada decisão, para que seja uma decisão acertada.

\subsubsection{Matemática Financeira no Ensino Médio}

Existe uma abordagem financeira tratada como conteúdo em sala de aula para alunos do ensino médio de escolas públicas e privadas. O conteúdo é abordado dentro da disciplina "matemática" e chama-se "matemática financeira".

Para Dante (2001, p. 293), "entre inúmeras aplicações da Matemática está a de auxiliar na resolução de problemas de ordem financeira, como cálculo do valor de prestações, pagamento de impostos, rendimento de poupança e outros". As noções de matemática financeira ensinadas nas escolas oferecem ao aluno a oportunidade de aprendizado sobre conceitos básicos que podem auxiliá-lo ao tomar decisões simples, que envolvam: razão e proporção, porcentagem, juros, juros simples, juros compostos e desconto simples e diversos conceitos, como: capital, tempo e taxa de juros (IEZZI et al., 1997, p. 178).

A abordagem do assunto é feita de forma superficial e restrita, não disponibilizando ao aluno informações que realmente possam levá-lo a uma reflexão sobre a decisão a ser tomada. Não se trata, por exemplo, de conteúdos como consumo responsável, do valor do dinheiro e sua relação com o trabalho, das vantagens da poupança, dos riscos do crédito, das ferramentas para gerenciamento do dinheiro, da diferença entre ativo e passivo, de noções do funcionamento do mercado, de aposentadoria ou de investimentos. 


\subsubsection{Comentários sobre Educação Financeira Pessoal no Ensino Médio}

A inserção da educação financeira como conteúdo programático nas escolas americanas derivou da necessidade percebida por sociedade, empresas públicas e privadas, tornando os Estados Unidos pioneiro nesta ação. No Brasil, existem estudiosos que mostram-se realmente interessados na inclusão deste conteúdo nas escolas de ensino fundamental e médio.

O Instituto de Educação Ivoti no Rio Grande do Sul trabalha a educação financeira como um projeto interdisciplinar, envolvendo várias áreas do conhecimento, como matemática, história, ética/filosofia e informática. Estas informações são passadas para grupos de alunos interessados no currículo facultativo. As aulas são de duas horas de duração por semana e objetivam

Criar condições para que os estudantes, independente da idade, possam refletir a respeito da responsabilidade de cada um no planejamento e administração econômica, aprendendo a dar importância ao hábito de economizar, gerando consciência de investimentos em qualidade de vida (INSTITUTO DE EDUCAÇÃO IVOTI, 2009).

Por parte do governo federal não há muita movimentação para que as idéias sobre educação financeira ensinada na formação básica do cidadão se tornem realidade. Há políticos que defendem fortemente o posicionamento da importância da difusão da educação financeira dentro das escolas, discutindo projetos e formas como esta iniciativa pode se conceber, porém, até o momento pouca ou nenhuma ação mais efetiva surtiu efeito. 


\section{MÉTODOS E TÉCNICAS DE PESQUISA}

Esse capítulo expõe o tipo de pesquisa realizada, as variáveis de pesquisa, as características da população, os critérios para definição da amostra, os instrumentos utilizados para a coleta de dados e as técnicas de coleta e análise dos dados coletados.

\subsection{Delineamento da Pesquisa}

Para Gil (1996) a pesquisa baseada em seus objetivos gerais pode ser dividida em três grandes grupos: exploratórias, descritivas e explicativas.

Por se tratar de uma área de estudos incipiente, existe pequena quantidade de artigos e pesquisas científicas voltadas para a educação financeira pessoal no Ensino Médio. Segundo Cooper e Schindler (2003, p. 131) "a área de investigação pode ser tão nova ou tão vaga que o pesquisador precisa fazer uma exploração a fim de saber algo sobre o problema enfrentado pelo administrador".

A pesquisa realizada visou a obtenção de melhor entendimento sobre o assunto, explorando um pouco mais a área de pesquisa. Caracteriza-se, então, como exploratória. "Estas pesquisas tem como objetivo proporcionar maior familiaridade com o problema, com vistas a torná-lo mais explícito ou a construir hipóteses" (GIL, 1996, p. 45).

É também uma pesquisa descritiva, pois de acordo com Vergara (2007), torna evidente particularidades de certa população ou de determinado fato de natureza moral ou social. Buscou-se levantar percepções dos estudantes de Ensino Médio no que se refere a educação financeira pessoal.

\subsection{Descrição das Variáveis de Pesquisa}

As variáveis relevantes para se atingir os objetivos da pesquisa são percebidas como fundamentais para $\circ$ fornecimento de informações verdadeiramente confiáveis.

A primeira variável é o perfil dos estudantes. Esta variável irá identificar e caracterizar o contexto vivido pelos estudantes de quem os dados foram coletados. 
Como segunda variável está a relevância do ensino da educação financeira pessoal e seus conteúdos para se estimar a relevância do tema, os assuntos considerados de maior interesse e os assuntos considerados já de domínio pelo estudante. Outra variável interessante para a pesquisa são os comportamentos e padrões de gasto e consumo que poderão fornecer maior credibilidade às informações fornecidas no questionário.

\subsection{Caracterização do Setor}

Segundo o Censo Escolar da Educação Básica 2008, realizado pelo Instituto Nacional de Estudos e Pesquisas Educacionais Anísio Teixeira (INEP), o Brasil possui 26.665 escolas que disponibilizam o Ensino Médio para sua população. Dessas, 204 encontram-se no Distrito Federal, sendo 109 escolas particulares, 94 Estaduais e 1 Federal.

O Distrito Federal contou com 17.257 alunos concluintes do Ensino Médio no ano de 2008 dentre os 98.287 alunos do Centro-Oeste e 1.189 .507 alunos em todo o Brasil. Destacou-se como o segundo melhor Estado colocado da rede pública de acordo com dados coletados no Exame Nacional de Ensino Médio (ENEM). O ENEM avalia o aluno e não a escola sobre seu grau de proficiência em relação às habilidades e competências que se espera do aluno ao final do Ensino Médio (ENEM).

\subsection{População e Amostra}

A população a ser pesquisada por meio de questionários é a de alunos de escolas públicas e privadas da terceira série do Ensino Médio do Distrito Federal. Já os participantes das entrevistas se caracterizam como professores de matemática e coordenadores de escolas de Ensino Médio do DF.

Será feira uma pesquisa com amostra não probabilística e por conveniência, de acordo com Cooper e Schindler (2003), pois o número de alunos pesquisados foi definido de acordo com a facilidade de acesso a cada escola e da abertura dada pelo professor para a realização da pesquisa. 
A amostra selecionada consiste em duas escolas, sendo uma pública e uma privada. A escola pública onde foi realizada a pesquisa é o Centro de Ensino Médio Setor Oeste (CEMSO), localizado na SGAS 912/913 Módulo D, Asa Sul, Brasília, DF. O CEMSO possui um total de 1.087 alunos matriculados, fazendo parte destes, 293 alunos da terceira série do Ensino Médio. É uma escola com grande reconhecimento dentro de sua esfera e caracteriza-se como a escola pública do DF com maior nota no ENEM 2009.

O Centro Educacional Galois foi a escola particular onde realizou-se a pesquisa. O colégio possui 906 alunos matriculados no Ensino Médio, sendo aproximadamente 400 alunos da terceira série. Localiza-se na SGAS 902, Asa Sul, Brasília, DF. Caracteriza-se como a escola de maior pontuação no ENEM do DF.

Da rede pública foram coletadas através de questionários as percepções de 68 alunos e foram realizadas duas entrevistas, uma com um professor de matemática e outra com um coordenador pedagógico. Da rede particular foram coletados dados de 85 alunos e foram entrevistados um professor de matemática e um diretor pedagógico.

Ao todo, foram coletados 153 questionários com informações e percepções de alunos da terceira série do Ensino Médio e entrevistados dois professores, um coordenador e um diretor pedagógico.

\subsection{Procedimentos e Instrumentos Utilizados na Coleta e Análise dos Dados}

A coleta dos dados ocorreu através da aplicação de questionários a alunos da terceira série do Ensino Médio do Distrito Federal e da realização de entrevistas junto a coordenadores pedagógicos e professores de matemática das escolas pesquisadas.

Os questionários foram aplicados aos alunos pelo pesquisador com o auxílio dos professores de matemática das próprias escolas em turmas de acordo com a conveniência da escola e do professor.

A compilação dos dados foi feita no SPSS 7.0, onde a análise descritiva das informações coletadas foi efetivada. O programa tornou-se essencial para se obter o resultado da pesquisa, uma vez que freqüências são calculadas com 
facilidade para cada questão e também foi possível elaborar gráficos a partir das porcentagens respondidas em cada item. Todas estas informações auxiliaram o pesquisador a entender melhor as informações coletadas.

As entrevistas foram agendadas com um professor de matemática e um coordenador pedagógico de cada escola pesquisada. Uma análise de conteúdo das entrevistas fez-se ideal para tratar as informações obtidas.

O questionário (Apêndice 1) utilizado originou-se de uma adaptação feita pelo pesquisador tendo como base uma pesquisa similar realizada no Brasil voltada para estudantes do Ensino Superior. O questionário consultado foi elaborado por Matta (2007).

O questionário foi adaptado para a linguagem utilizada pela população pesquisada, de alunos de escolas públicas e particulares da terceira série do Ensino Médio do Distrito Federal. Algumas questões foram retiradas e outras adicionadas para que houvesse alinhamento entre os objetivos desta pesquisa e o instrumento de coleta de dados.

Está dividido em 11 questões, sendo que as questões de 1 a 5 são para identificar melhor o perfil dos estudantes pesquisados. As questões de 6 a 11 são focadas na coleta de dados que possibilitasse identificar a importância dada a educação financeira pessoal, as demandas pelo tema e os conteúdos prioritários. Neste ponto do questionário é exposto aos alunos o conceito de educação financeira pessoal para posterior coleta de impressões a respeito do tema. Na questão 6 verifica-se a impressão para a importância da obtenção de informações financeiras pessoais. A questão 7 procura identificar os assuntos que geram maior interesse entre os alunos, envolvendo: informações sobre o uso de cartão de crédito, empréstimos pessoais, poupança, financiamentos, consumo planejado, bolsa de valores, juros, gerenciamento de gastos e aposentadoria. O estudante deveria escolher cinco itens dentre estes e enumerá-los em ordem de importância. A questão 8 foi elaborada para verificar sobre quais temas o entrevistado considera já possuir informações suficientes para tomar decisões assertivas, envolvendo os mesmos assuntos descritos na questão anterior. As questões 9 e 10 questionam se os alunos já tiveram alguma aula sobre educação financeira pessoal e coletam opiniões sobre o ensino da educação financeira na escola. A última questão 
enumera 16 itens, avaliados segundo uma escala likert, envolvendo hábitos de gestão financeira pessoal.

O roteiro de entrevista (Apêndice 2) seguido foi construído tendo como principal questionamento ao entrevistado a relevância do ensino de educação financeira pessoal para a formação do cidadão brasileiro. Conceitua-se a educação financeira pessoal e questiona-se sobre a responsabilidade por atuar diretamente na educação financeira e se é percebida alguma ação por parte do responsável. Em seguida, questiona-se a possibilidade da escola fomentar o ensino da educação financeira. Por último, pede-se que o entrevistado indique 5 assuntos sobre educação financeira pessoal que são percebidos como mais relevantes para a formação de um adulto capaz de administrar sua vida financeira de forma saudável.

O pré-teste dos instrumentos de coleta de dados consistiu na aplicação do questionário a três estudantes da terceira série do Ensino Médio e a um professor de finanças da Universidade de Brasília. O roteiro de entrevista foi testado anteriormente junto a um professor de finanças da Universidade de Brasília e a um coordenador pedagógico. Os feedbacks gerados foram essenciais para a adaptação do questionário e do roteiro de entrevista aos objetivos propostos pela pesquisa.

\subsection{Período de Realização da Pesquisa}

A pesquisa teve início na primeira semana de março quando foi definido o tema de pesquisa e a forma como esta se daria, assim como seus objetivos gerais e específicos. Em seguida fez-se necessária uma ampla busca na produção científica gerada até então na área para o desenvolvimento do referencial teórico, o que levou cerca de 6 semanas, incluindo também o tempo para a estruturação e planejamento da pesquisa. O terceiro momento bastante importante foi a coleta de dados, que aconteceu entre 0 dia 25 de maio $o$ dia 5 de junho. Por fim, houve a análise dos dados, que englobou mais três semanas até a segunda semana de junho e depois foram elaborasse as considerações finais. A pesquisa teve duração de 15 semanas. 


\subsection{Comentários Sobre o Processo de Coleta de Dados}

A coleta de dados ocorreu conforme o planejado. As duas escolas onde a pesquisa foi realizada perceberam a pesquisa de forma positiva. Houve também grande interesse por parte dos alunos a respeito do tema, tornando o trabalho ainda mais satisfatório.

Por conta da falta de abertura em outras instituições de ensino para a pesquisa, a amostra utilizada foi abaixo do esperado, não em termos de número de questionários, mas em números de escolas, uma vez que não se englobou realidades mais distintas de perfis de alunos. Uma quantidade maior de escolas geraria informações que seriam de interesse para a pesquisa, pois garantiriam maior abrangência das conclusões do estudo. 


\section{APRESENTAÇÃo E ANÁLISE DOS RESULTADOS DA PESQUISA}

Os dados coletados estão disponibilizados para o leitor partindo-se de uma seqüência onde inicialmente se trata de informações sobre o perfil dos estudantes de quem os dados foram coletados, para que, em seguida, seja realizada uma análise mais efetiva envolvendo a amostra e outros aspectos importantes da pesquisa.

Durante a análise, os objetivos da pesquisa são relembrados e discutidos resultando em um melhor entendimento sobre o assunto. É importante para a pesquisa o entendimento da percepção por parte dos alunos, primeiramente, da relevância do ensino da educação financeira pessoal e também dos temas onde se percebe maior carência no ensino da educação financeira pessoal.

Ainda com os estudantes, se discorre sobre a coerência entre as informações coletadas de demandas e domínios de educação financeira pessoal com os seus comportamentos relacionados ao gerenciamento de recursos. Houve a intenção de entender melhor a relação dos alunos com o gerenciamento de gastos, os pensamentos de investimento, poupança e consumo.

Após a análise dos dados coletados dos alunos, buscou-se verificar a existência de alguma relação entre as percepções dos estudantes e as percepções de professores e coordenadores. Este ponto da análise poderá fornecer informações fundamentais para se atingir os objetivos da pesquisa, entendendo-se as percepções dos envolvidos com o tema.

\subsection{Perfil dos Estudantes da Terceira Série do Ensino Médio}

Da população pesquisada, $55 \%$ é do sexo masculino e $45 \%$ do sexo feminino. As idades dos estudantes variam de 15 a 19 anos, sendo que $90 \%$ destes com idade igual a 17 anos. A renda familiar é distribuída conforme a tabela 1, em números de salários mínimos. 
Tabela 1 - Freqüência e Porcentagem de Alunos Classificados de Acordo com a Renda Familiar Mensal

\begin{tabular}{|c|c|c|c|c|}
\hline $\begin{array}{c}\text { Renda Familiar } \\
\text { (Em salários mínimos) }\end{array}$ & Frequência & Porcentagem & $\begin{array}{l}\text { Porcentagem } \\
\text { Válida }\end{array}$ & $\begin{array}{l}\text { Porcentagem } \\
\text { Cumulativa }\end{array}$ \\
\hline Até 1 & 3 & 2.0 & 2.0 & 2.0 \\
\hline De 1 a 3 & 18 & 11.8 & 12.1 & 14.1 \\
\hline De 3 a 5 & 15 & 9.8 & 10.1 & 24.2 \\
\hline De 5 a 10 & 28 & 18.3 & 18.8 & 43.0 \\
\hline De 10 a 20 & 25 & 16.3 & 16.8 & 59.7 \\
\hline Acima de 20 & 60 & 39.2 & 40.3 & 100.0 \\
\hline Total & 149 & 97.4 & 100.0 & \\
\hline Não respondidos & 4 & 2.6 & & \\
\hline Total & 153 & 100.0 & & \\
\hline
\end{tabular}

Fonte: Dados de pesquisa, elaborado pelo autor em 06/2009.

Portanto, a família da maioria dos entrevistados tem renda acima de 20 salários mínimos. A faixa salarial que ocupa a segunda posição com maior número de alunos é a de famílias que recebem entre 5 e 10 salários mínimos.

Com relação ao recebimento de mesada e da realização de atividade remunerada, $25 \%$ dos alunos da rede pública recebem mesada com valor médio de $R \$ 125,00$. Na rede particular, $41 \%$ dos alunos recebem mesada e o valor médio é de $\mathrm{R} \$ 228,00$. Da população total pesquisada, $35,3 \%$ recebe mesada, que tem como valor médio $\mathrm{R} \$ 194,00$.

Mais de $10 \%$ dos alunos afirma possuir alguma fonte de renda independente da de seus responsáveis, sendo destes, 83,33\% da rede pública. Em média os alunos recebem $\mathrm{R} \$ 349,00$ de renda independente.

Estes dados mostram que parte dos alunos da terceira série do Ensino Médio já lida com decisões financeiras atreladas a uma quantia recebida mensalmente. Mesmo os estudantes que não recebem mesada e não exercem atividade remunerada também tomam decisões financeiras ligadas a gerenciamento de gastos, juros, poupança, investimento e consumo. 


\subsection{Relevância do Ensino da Educação Financeira Pessoal}

Buscou-se identificar percepções sobre a relevância do ensino da educação financeira pessoal em escolas públicas e privadas do Distrito Federal. A figura 1 ilustra as informações coletadas desta população.

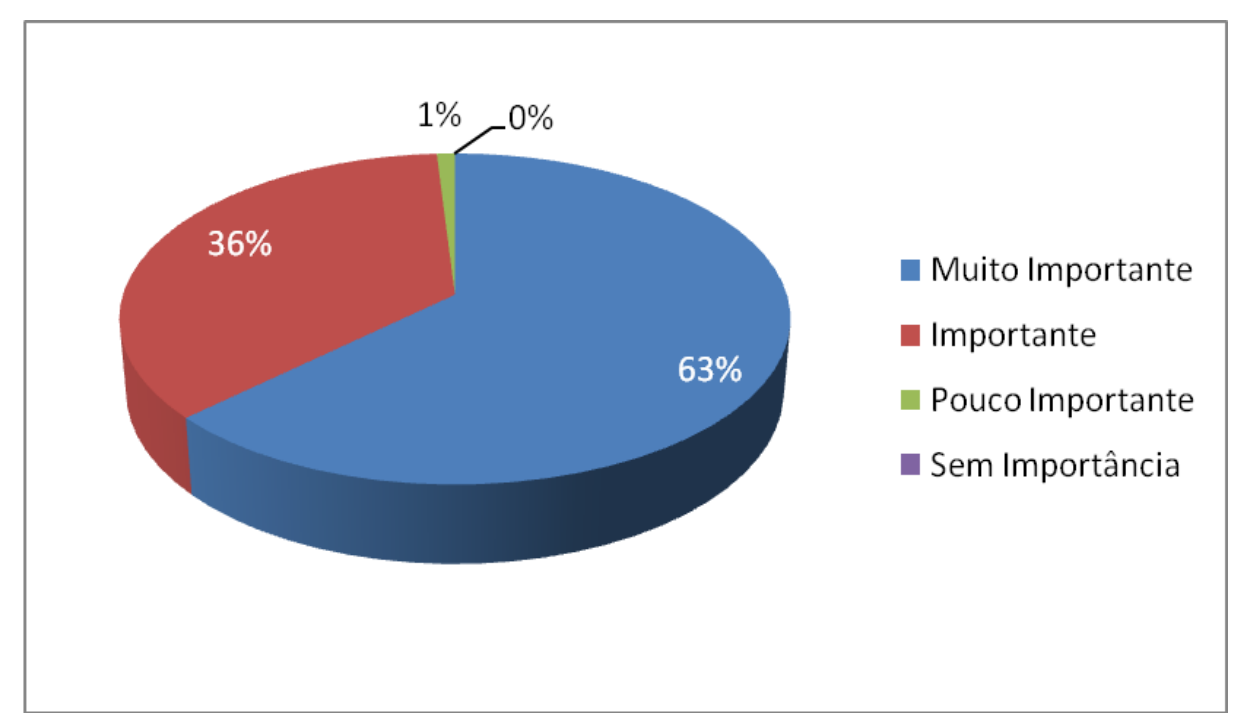

Figura 1 - Percepção sobre a Importância da obtenção de Informações Voltadas à Educação Financeira Pessoal

Fonte: Dados de pesquisa, elaborado pelo autor em 06/2009.

Percebe-se, a partir destes dados, que na opinião de $63 \%$ dos estudantes da terceira série do Ensino Médio, obter informações voltadas à educação financeira pessoal é "muito importante". A classificação "importante" está em segundo lugar com $36 \%$. Apenas $1 \%$ dos estudantes considera a obtenção de informações sobre educação financeira pessoal "pouco importante" e nenhum estudante considerou o assunto "sem importância".

Portanto, o tema firma-se como de interesse dos alunos da terceira série do Ensino Médio. Considerando que estes indivíduos lidam com decisões que envolvem valores monetários, gerenciam suas despesas e tomam decisões financeiras, os resultados da pesquisa indicam que o tema merece atenção por parte de pais, governo e escola.

Entretanto, os dados coletados apontam para outra realidade, onde o que se observa é o descuido em se tratando do tema ou a despreocupação das pessoas responsáveis no que tange à educação financeira pessoal. Existe uma lacuna entre 
a importância percebida por parte dos alunos, como mostra a figura 1 e o efetivo suprimento desta necessidade, como mostra a figura 2.

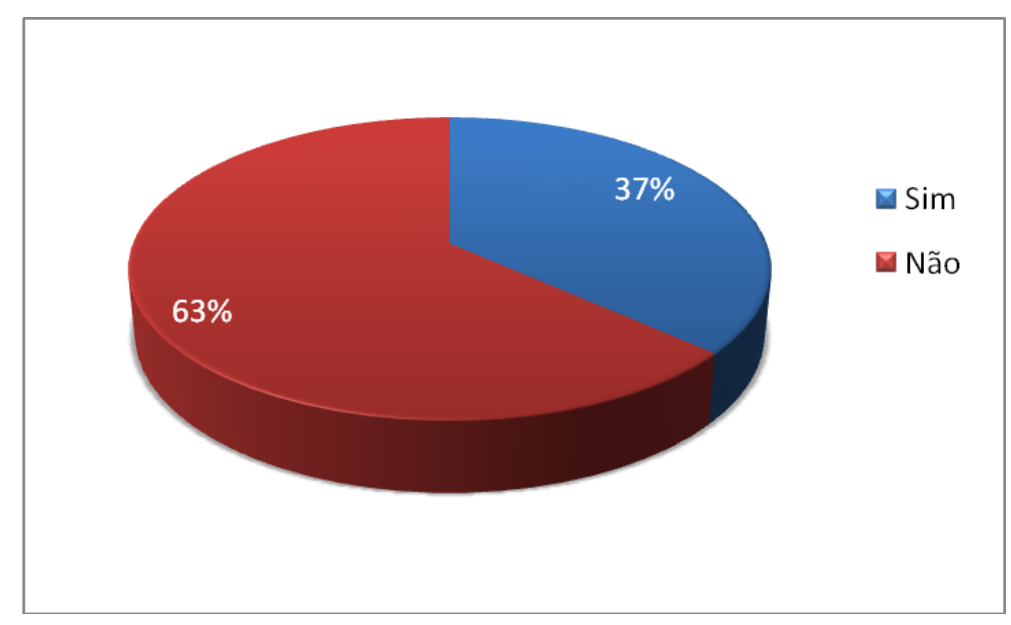

Figura 2 - Porcentagem de Alunos que Tiveram Alguma Aula Cujo Conteúdo Ministrado Estava Relacionado à Educação Financeira Pessoal

Fonte: Dados de pesquisa, elaborado pelo autor em 06/2009.

Dos alunos, 63,4\% afirmam nunca ter tido uma aula sobre educação financeira pessoal, o que demonstra defasagem no ensino básico da população, uma vez que em países desenvolvidos, como no caso da Inglaterra, a educação financeira é matéria obrigatória nas escolas. Da mesma forma, outros governos têm trabalhado para que informações sobre educação financeira pessoal estejam presentes nos currículos escolares das crianças e dos jovens (MATTA, 2007). Nos Estados Unidos, quase $60 \%$ dos Estados instituíram obrigatoriedade para o ensino da educação financeira pessoal em escolas secundárias (SAVOIA, SAITO; SANTANA, 2007).

Somando-se a esta evidência, os dados da figura 3 indicam, na opinião do aluno, se a educação financeira pessoal deveria ser ensinada na escola ou não. 


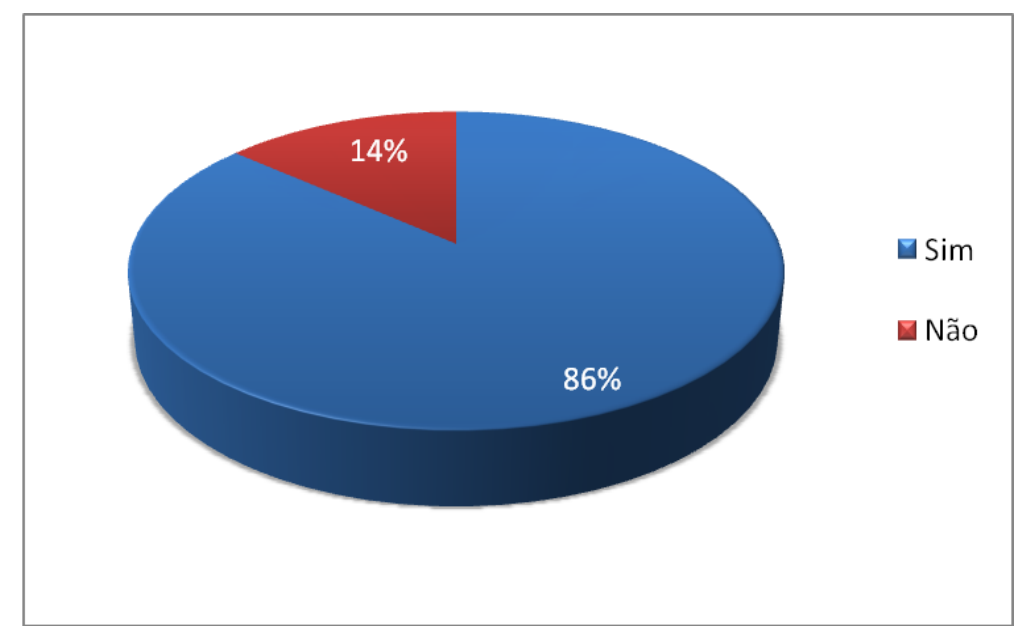

Figura 3 - Porcentagem de Alunos que Consideram que a Educação Financeira Pessoal Deveria Ser Ensinada na Escola

Fonte: Dados de pesquisa, elaborado pelo autor em 06/2009.

Tem-se que $86 \%$ dos alunos concordam que a educação financeira pessoal deveria ser ensinada na escola. Percebe-se novamente uma lacuna entre as percepções dos alunos, que consideram importante obter informações sobre educação financeira pessoal e acreditam que a escola seria um momento adequado para a abordagem do tema, mas que em sua maioria nunca tiveram uma aula sobre educação financeira pessoal.

Existe um grande desafio lançado para os responsáveis pela formação básica do cidadão. No momento em que se observa uma carência neste processo, é necessário uma ação que gere algum retorno frente a distância percebida entre percepções e a realidade.

\subsection{Importância dos Conteúdos de Educação Financeira Pessoal}

Identificar percepções a respeito da importância de cada assunto dentro da educação financeira pessoal é de fundamental importância para os objetivos da pesquisa, que visa enumerar os assuntos por ordem de prioridade. Esta classificação é importante também para entender melhor as demandas por conteúdos ligados à área de pesquisa, pois a educação financeira pessoal é vista como fundamental para o bem estar da sociedade.

A tabela 2 ilustra os conteúdos de educação financeira pessoal para os quais os alunos da terceira série do Ensino Médio público e privado afirmam ter 
maior interesse em obter mais informações. Os assuntos estão enumerados em ordem de prioridade para facilitar a análise.

Tabela 2 - Assuntos de Educação Financeira Pessoal em Ordem de Importância na Percepção de Alunos da Terceira Série do Ensino Médio

\begin{tabular}{|c|l|r|}
\hline Ordem & Assunto & Índice \\
\hline 1 & Bolsa de Valores & 2.49 \\
\hline 2 & Gerenciamento de Gastos & 2.69 \\
\hline 3 & Uso do Cartão de Crédito & 2.87 \\
\hline 4 & Consumo Planejado & 2.95 \\
\hline 5 & Poupança & 3 \\
\hline 6 & Juros & 3.01 \\
\hline 7 & Empréstimos Pessoais & 3.38 \\
\hline 8 & Financiamentos & 3.48 \\
\hline 9 & Aposentadoria & 3.66 \\
\hline
\end{tabular}

Fonte: Dados de pesquisa, elaborado pelo autor em 06/2009.

A tabela destaca o grande interesse dos alunos em obter mais informações a respeito do tema "bolsa de valores". Este conteúdo chama bastante atenção dos alunos, que acompanham a importância conquistada pela bolsa de valores tanto para investidores pessoa física quanto para as empresas e para o governo, reafirmando o crescente interesse da população em obter mais informações sobre o assunto.

O segundo tema que merece destaque é o de gerenciamento de gastos. Os alunos consideram importante obter mais informações sobre a forma como gerenciam seus gastos. Em seguida, o tema percebido com maior importância é o de uso de cartão de crédito, o que constata a abrangência da oferta deste serviço a uma população cada vez mais jovem e mostrando-se necessário instruir quanto ao uso de serviços financeiros ofertados a esta população.

Dentre os assuntos que foram considerados menos interessantes, o que se destaca é a falta de interesse para o assunto aposentadoria. Para Halfeld (2004, p. 103) "o maior desafio financeiro de nossas vidas não é a compra de um automóvel novo ou da casa própria. O mais difícil de tudo é ter recursos suficientes para nos mantermos com dignidade durante a velhice", o que indica que esta falta de interesse para o assunto pode estar ligada à cultura de despreocupação com a aposentadoria, ou então, pode-se dizer que, pela idade dos entrevistados, as preocupações acerca do assunto ainda não são consideradas, uma vez que a 
maioria dos estudantes não trabalha e possui outros objetivos neste momento, vinculados não diretamente ao de possuir recursos suficientes para se viver uma velhice de forma saudável. Mesmo assim, despertar a consciência dos alunos a respeito do tema é importante. Quanto mais cedo se inicia o planejamento da aposentadoria, maiores são os retornos conseguidos (MATTA, 2007).

Caixa 1 - Indicador de Percepção de Importância

A tabela de assuntos de educação financeira pessoal em ordem de importância na percepção de alunos da terceira série do Ensino Médio foi construída a partir do cálculo do indicador de percepção de importância (I). Este indicador foi calculado de acordo com a ordem de percepção de cada aluno considerando a importância dos assuntos, conforme fórmula a seguir:

$$
I=\frac{\sum_{1}^{\text {ne }} \mathrm{Pe}}{\text { ne }}
$$

Onde Pe é a percepção da importância de cada assunto para os alunos e ne é o número de estudantes que auferiram importância para o item.

O valor Pe foi dado por cada estudantes em uma escala de 1 a 5 , sendo 1 o assunto mais importante e 50 assunto menos importante. Sendo assim, quanto mais baixo o I, maior é a importância do assunto para os alunos.

\subsection{Domínio de Conteúdos de Educação Financeira Pessoal}

Em relação ao domínio de conteúdos de educação financeira pessoal, foram coletados dados que ilustrassem ao pesquisador a segurança que os alunos tem ao tomar decisões sobre estes conteúdos, sendo estas suficientes ou não. $A$ figura 4 indica o número de conteúdos que os alunos consideram já possuir informações suficientes para tomar decisões. 


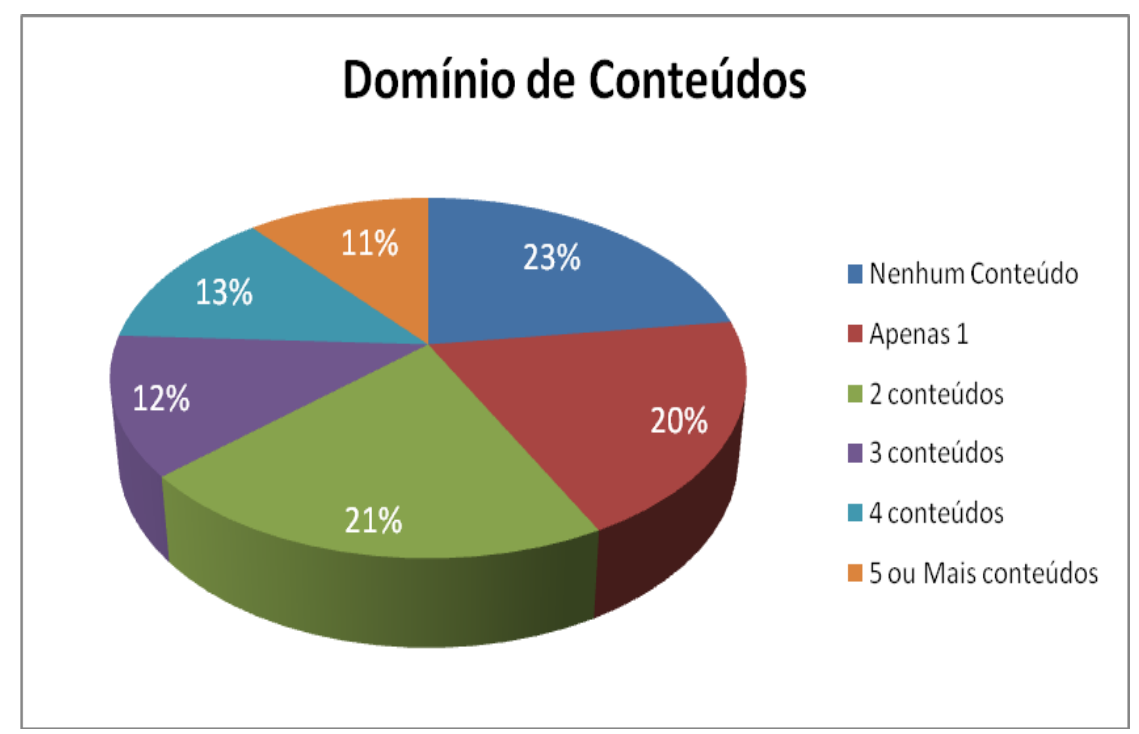

Figura 4 - Porcentagem do Número de Conteúdos Mencionados como Dominados pelos Estudantes Fonte: Dados de pesquisa, elaborado pelo autor em 06/2009.

A maioria dos alunos (77\%) afirma já possuir informação suficiente para tomar decisões a respeito de pelo menos um assunto, enquanto que $23 \%$ dos estudantes afirmam não possuir nenhuma informação.

Apesar de o tema não ser trabalhado em sala de aula, pode-se dizer que os alunos tem domínio de alguns assuntos de educação financeira pessoal. No entanto, percebe-se que estas informações são limitadas, restringido-se a poucos conteúdos, enquanto que com a difusão de informações sobre o tema, o aluno teria maior segurança ao tomar decisões que envolvessem os assuntos trabalhados em sala de aula.

Um dado que contribui para esta análise é que do total de estudantes, apenas $11 \%$ afirma ter domínio de 5 ou mais conteúdos, o que demonstra que grande parte dos assuntos ainda é desconhecido pelos alunos do Ensino Médio.

Os assuntos de educação financeira pessoal tidos como dominados pelos alunos foram colocados em uma figura para melhor visualização, estando estes em ordem crescente em se tratando do número de alunos que afirmam ter domínio da informação para tomar decisões sobre o tema, conforme figura 5. 


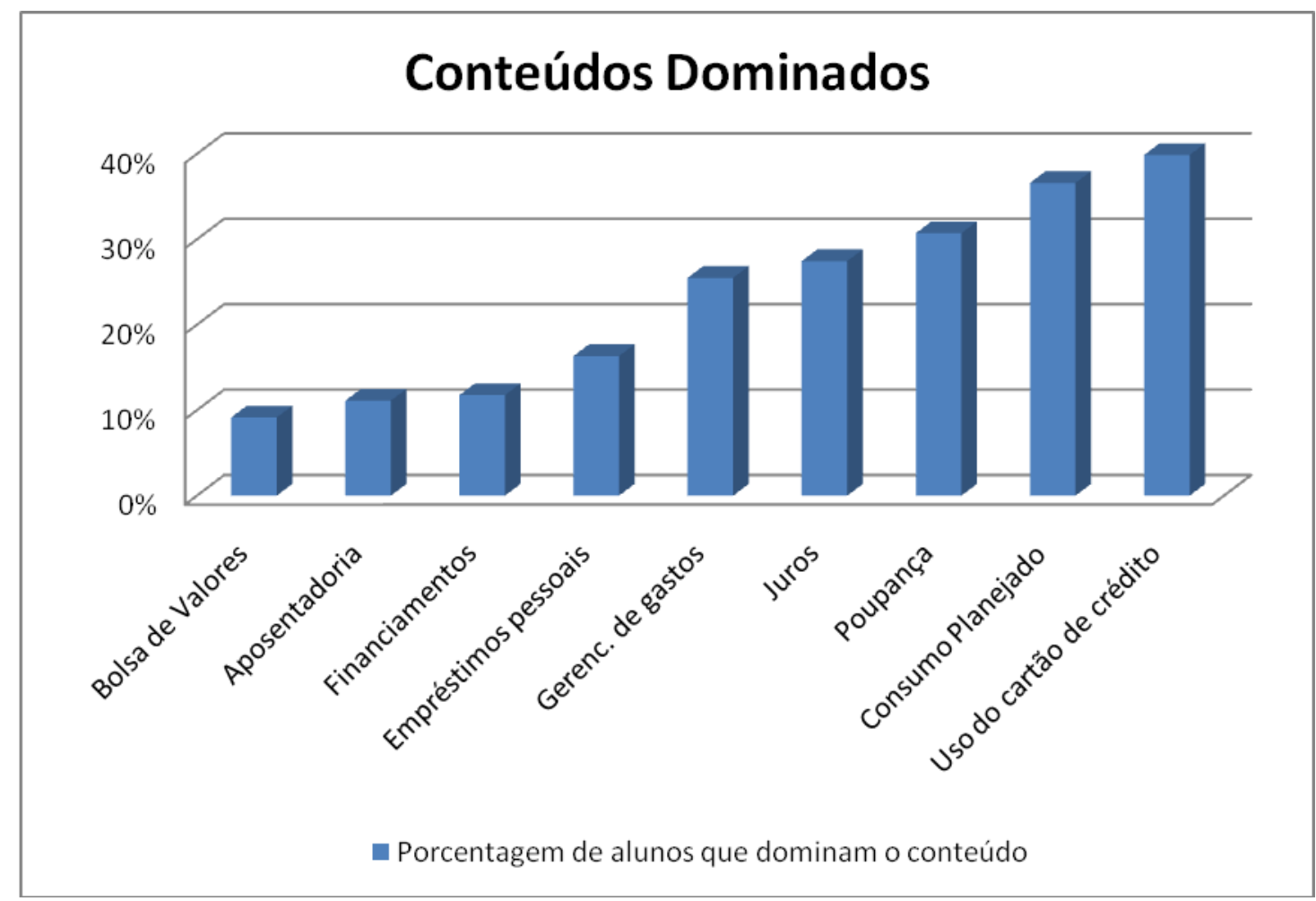

Figura 5 - Porcentagem de Alunos que Afirmam ter Domínio sobre Cada Conteúdo de Educação Financeira Pessoal

Fonte: Dados de pesquisa, elaborado pelo em 06/2009.

Menos de $10 \%$ dos alunos concordam em ter informações suficientes para tomar decisões sobre bolsa de valores, sendo este assunto tido como o que os estudantes menos tem conhecimento. Em seguida, o assunto aposentadoria está presente com $11 \%$ de domínio pelos estudantes secundaristas.

É interessante observar que cerca de $40 \%$ dos estudantes afirmam possuir informações sobre consumo planejado ou sobre uso do cartão de crédito. Estes dados mostram que de certa forma estes assuntos estão mais presentes na vida dos alunos de Ensino Médio, possibilitando a estes dominar o assunto e poder tomar decisões a respeito.

Por estes dados, pode-se dizer que o conhecimento adquirido pelos estudantes que afirmaram ter domínio dos conteúdos da figura 3 foi obtido independentemente de alguma ação por parte da escola, visto que a maioria dos estudantes afirmou não ter tido nenhuma aula sobre conteúdos de educação financeira pessoal. 


\subsection{Conteúdos de Educação Financeira Pessoal Prioritários}

Um dos objetivos específicos da pesquisa constitui-se em determinar os conteúdos percebidos como prioritários para o ensino da educação financeira pessoal na formação básica dos cidadãos brasileiros. Uma vez que grande parte dos estudantes do Ensino Médio nunca teve contato com o tema em sala de aula, faz-se necessário identificar quais dos conteúdos podem ser ministrados de imediato, ou seja, são prioritários, a fim de se corrigir uma falha existente no ensino da educação financeira pessoal dos cidadãos do Distrito Federal.

A tabela 3 apresenta, em ordem de prioridade, os assuntos de educação financeira pessoal. Entende-se que os assuntos prioritários são aqueles percebidos pelos alunos com maior importância e os quais os alunos têm menor domínio.

Tabela 3 - Conteúdos em Ordem de Prioridade

\begin{tabular}{|c|l|}
\hline Prioridade & \multicolumn{1}{c|}{ Conteúdos } \\
\hline 1 & Bolsa de Valores \\
\hline 2 & Gerenciamento de Gastos \\
\hline 3 & Empréstimos Pessoais \\
\hline 4 & Financiamentos \\
\hline 5 & Aposentadoria \\
\hline 6 & Uso do Cartão de Crédito \\
\hline 8 & Consumo Planejado \\
\hline 9 & Poupança \\
\hline
\end{tabular}

Fonte: Dados de pesquisa, elaborado pelo autor em 06/2009.

A bolsa de valores é um dos temas percebidos como de maior interesse pelos alunos e que possui menor domínio por parte dos mesmos. É um assunto que merece destaque pela relevância que tem para a sociedade, sendo importante instruir os futuros investidores sobre seu funcionamento, uma vez que os jovens mostram-se cada vez mais interessados em investir e o volume de negócios tem crescido nos últimos anos. (BOVESPA)

Outro tema percebido como prioritário é o gerenciamento de gastos. É consentimento entre os especialistas na área que a forma como o indivíduo gerencia os gastos faz total diferença entre a prosperidade e a escassez de recursos considerando-se tanto um pequeno período de tempo quanto um grande. 
Para Matta (2007 apud ARAUJO, 1999; ONU, 2003; MORTON, 2005; LUCEY e GIANNELO, 2006) o Estado deveria participar de forma ativa e constante no que diz respeito a alfabetização financeira de seu povo, incluindo o ensino em escolas e universidades. A participação do Estado poderia fomentar a difusão de informações de educação financeira pessoal tidos como prioritários, o que possibilitaria maior domínio sobre o tema por parte de seus cidadãos, estando estes mais preparados para gerir suas finanças de forma saudável.

\subsection{Comportamentos que Indicam Gestão Adequada dos Recursos Financeiros Pessoais}

A fim de avaliar como os estudantes da terceira série do Ensino Médio lidam com o assunto "dinheiro", levantou-se uma série de comportamentos que possibilitariam concluir se a gestão de recursos financeiros está sendo feita de maneira adequada por estes estudantes. Estes dados retratam decisões de gerenciamento de gastos, consumo, investimento e juros que são tomadas pelos estudantes, assim como estratégias financeiras utilizadas para melhor atender às suas necessidades.

Alguns pontos merecem mais cuidado na análise dos dados principalmente os comportamentos que indicam gestão adequada dos recursos financeiros pessoais, conforme indica a tabela 4 . 
Tabela 4 - Porcentagem de Estudantes que Afirmam ter Comportamentos que Indicam Gestão Adequada dos Recursos Financeiros Pessoais

\begin{tabular}{|l|c|c|c|c|c|}
\hline $\begin{array}{c}\text { Comportamentos que Indicam Gestão } \\
\text { Adequada dos Recursos Financeiros } \\
\text { Pessoais }\end{array}$ & Nunca & $\begin{array}{c}\text { Quase } \\
\text { Nunca }\end{array}$ & $\begin{array}{c}\text { Quase } \\
\text { Sempre }\end{array}$ & Sempre & $\begin{array}{c}\text { Sem } \\
\text { Resposta }\end{array}$ \\
\hline $\begin{array}{l}\text { Preocupa-se em gerenciar melhor o seu } \\
\text { dinheiro }\end{array}$ & $0 \%$ & $6 \%$ & $37 \%$ & $57 \%$ & $1 \%$ \\
\hline $\begin{array}{l}\text { Identifica a existência de juros ao comprar } \\
\text { um produto à crédito (ex.: juros embutidos) }\end{array}$ & $16 \%$ & $25 \%$ & $27 \%$ & $31 \%$ & $1 \%$ \\
\hline $\begin{array}{l}\text { Anota e controla os seus gastos pessoais } \\
\text { mensais (ex.: planilha de receitas e } \\
\text { despesas, caderno de anotações, etc.) }\end{array}$ & $44 \%$ & $26 \%$ & $16 \%$ & $14 \%$ & $1 \%$ \\
\hline $\begin{array}{l}\text { Está satisfeito com o sistema de controle } \\
\text { de suas finanças }\end{array}$ & $15 \%$ & $24 \%$ & $47 \%$ & $13 \%$ & $1 \%$ \\
\hline $\begin{array}{l}\text { Estabelece metas financeiras que } \\
\text { influenciam na administração do seu } \\
\text { dinheiro (ex.: Poupar uma quantia no ano) }\end{array}$ & $11 \%$ & $28 \%$ & $35 \%$ & $26 \%$ & $1 \%$ \\
\hline $\begin{array}{l}\text { Poupa visando a compra de um produto } \\
\text { mais caro }\end{array}$ & $6 \%$ & $20 \%$ & $41 \%$ & $33 \%$ & $1 \%$ \\
\hline $\begin{array}{l}\text { Poupa mensalmente sem ter } \\
\text { necessariamente a intenção de consumir } \\
\text { algo com o dinheiro poupado }\end{array}$ & $18 \%$ & $24 \%$ & $34 \%$ & $24 \%$ & $0 \%$ \\
\hline Pensa em investir o seu dinheiro & $8 \%$ & $21 \%$ & $31 \%$ & $39 \%$ & $1 \%$ \\
\hline Compara preços ao fazer compras & $3 \%$ & $12 \%$ & $39 \%$ & $46 \%$ & $0 \%$ \\
\hline
\end{tabular}

Fonte: Dados de pesquisa, elaborado pelo autor em 06/2009.

Primeiramente pode-se ressaltar a preocupação de grande parte dos estudantes em gerenciar melhor o seu dinheiro. Este dado mostra a abertura dada pelos alunos para assuntos que podem auxiliá-los na administração de seus recursos financeiros.

Outro comportamento bastante positivo tido como sempre exercido pelos estudantes é o de comparar preços ao fazer compras. Este comportamento é fundamental para o gerenciamento de gastos, o aumento da disponibilidade de recursos para outro fim e para a valorização do dinheiro que o aluno detém.

Mesmo assim, um dos comportamentos avaliados não está colaborando para a gestão financeira pessoal dos estudantes, que é o controle de gastos pessoais mensais. A maioria dos estudantes (44\%) concorda que nunca anotam e controlam seus gastos mensais. Este comportamento favorece o descontrole financeiro, uma vez que não se tem idéia do destino dos recursos disponíveis, havendo também dificuldade em se estimar os gastos por certo período de tempo e fazer previsões quanto ao acúmulo ou gasto de capital. O maior controle dos gastos poderia favorecer o jovem no momento de planejar seu fluxo de caixa de acordo com as suas necessidades, evitando gastos em exagero e desnecessários. 


\subsection{Comportamentos que Indicam Gestão Inadequada dos Recursos Financeiros Pessoais}

Com relação aos comportamentos que indicam uma gestão inadequada dos recursos financeiros, pode-se dizer, de modo geral, que são evitados pela maioria dos estudantes, conforme mostra a tabela 5.

Tabela 5 - Porcentagem de Estudantes que Afirmam ter Comportamentos que Indicam Gestão Inadequada dos Recursos Financeiros Pessoais

\begin{tabular}{|l|c|c|c|c|c|}
\hline $\begin{array}{c}\text { Comportamentos que Indicam Gestão } \\
\text { Inadequada dos Recursos Financeiros } \\
\text { Pessoais }\end{array}$ & Nunca & $\begin{array}{c}\text { Quase } \\
\text { Nunca }\end{array}$ & $\begin{array}{c}\text { Quase } \\
\text { Sempre }\end{array}$ & Sempre & $\begin{array}{c}\text { Sem } \\
\text { Resposta }\end{array}$ \\
\hline Compra por impulso & $23 \%$ & $59 \%$ & $15 \%$ & $3 \%$ & $0 \%$ \\
\hline $\begin{array}{l}\text { Paga suas contas em atraso } \\
\text { Seus gastos mensais ultrapassam o valor } \\
\text { recebido mensalmente }\end{array}$ & $61 \%$ & $30 \%$ & $7 \%$ & $1 \%$ & $1 \%$ \\
\hline $\begin{array}{l}\text { Não tem limite de gastos mensais, compra } \\
\text { tudo o que quer e quando quer }\end{array}$ & $72 \%$ & $19 \%$ & $8 \%$ & $1 \%$ & $0 \%$ \\
\hline $\begin{array}{l}\text { Prefere comprar um produto financiado a } \\
\text { juntar dinheiro para comprá-lo a vista }\end{array}$ & $64 \%$ & $24 \%$ & $10 \%$ & $1 \%$ & $1 \%$ \\
\hline
\end{tabular}

Fonte: Dados de pesquisa, elaborado pelo autor em 06/2009

Acima de $61 \%$ dos alunos afirmam nunca pagar suas contas em atraso, nunca deixar que seus gastos mensais ultrapassem o valor recebido mensalmente, ter limites de gastos mensais ou demonstra preferência pela compra de um produto à vista do que financiado.

Um dado que chama atenção é que apenas $23 \%$ dos estudantes concordam em nunca comprar por impulso, enquanto que 15\% afirmam quase sempre comprar por impulso. Este dado mostra o cuidado e a necessidade que deve-se ter em conscientizar a população com relação ao consumo. Existe uma idéia de consumo divulgada pelas propagandas veiculadas em jornais e rádios que vão contra o consumo responsável, o planejamento financeiro e o atendimento às 
necessidades básicas e afetam diretamente seu consumidor-alvo, muitas vezes jovens e despreparados para tomar tais decisões de forma segura e consciente.

\subsection{Comportamentos que Indicam Estratégias de Longo Prazo para as Finanças Pessoais}

Os comportamentos que indicam estratégias de longo prazo para as finanças pessoais estão apresentados na tabela 6.

Tabela 6 - Porcentagem de que Afirmam ter Comportamentos que Indicam Gestão Inadequada dos Recursos Financeiros Pessoais

\begin{tabular}{|l|c|c|c|c|c|}
\hline $\begin{array}{c}\text { Comportamentos que Indicam } \\
\text { Estratégias de Longo Prazo para as } \\
\text { Finanças Pessoais }\end{array}$ & Nunca & $\begin{array}{c}\text { Quase } \\
\text { Nunca }\end{array}$ & $\begin{array}{c}\text { Quase } \\
\text { Sempre }\end{array}$ & Sempre & $\begin{array}{c}\text { Sem } \\
\text { Resposta }\end{array}$ \\
\hline $\begin{array}{l}\text { Pensa em ser independente } \\
\text { financeiramente dos seus responsáveis 0 } \\
\text { mais rápido possível }\end{array}$ & $5 \%$ & $7 \%$ & $20 \%$ & $68 \%$ & $1 \%$ \\
\hline $\begin{array}{l}\text { Considera importante ter uma vida } \\
\text { financeira saudável }\end{array}$ & $0 \%$ & $2 \%$ & $3 \%$ & $95 \%$ & $0 \%$ \\
\hline
\end{tabular}

Fonte: Dados de pesquisa, elaborado pelo autor em 06/2009.

Quase $90 \%$ dos alunos dividem o pensamento de ser independente financeiramente dos seus responsáveis o mais rápido possível. Esta estratégia pode ser vista como dependente da geração de receita e conseqüentemente da necessidade de tomada de decisões financeiras mais freqüentes, criando a necessidade de obtenção de informações que auxiliem estes estudantes a gerir suas finanças de forma saudável.

Milhares de estudantes saem da educação básica sem noções mínimas de contabilidade para gerir seus recursos financeiros, ou sem informações que o permitam avaliar melhor entre duas alternativas de financiamento ou sem capacidade para decidir a contratação ou não de um novo plano de cartão de crédito ou sem saber muitas vezes o destino dos seus investimentos, que sem informação, tendem a se desfazer em pouco tempo. São estes mesmos estudantes que tem esta preocupação em ser independentes, mas não são instruídos sobre o que é preciso saber para ser independente e ter uma vida financeira saudável que tomam decisões diariamente e afetam seu bem estar por anos devido a uma decisão errada. 
Pode-se pensar que com a formação de novas gerações em relação a finanças pessoais, no futuro estes serão os maiores disseminadores do conhecimento, sendo grande aliado de qualquer política ou ação que fomente a discussão do tema para se gerar uma mudança de forma efetiva.

Outro dado interessante diz respeito ao conflito entre os objetivos dos estudantes e as informações disponibilizadas pelo ensino básico. Da amostra, 95\% dos estudantes consideram importante ter uma vida financeiramente saudável, o que pressupõe a necessidade de se instruir financeiramente estes indivíduos.

\subsection{Percepção de Professores e Coordenadores sobre Educação Financeira Pessoal}

Em relação a percepção de professores e coordenadores sobre educação financeira pessoal, as entrevistas realizadas possibilitaram a coleta de informações que ressaltam ainda mais a importância do conteúdo ser ministrado ainda na formação básica do cidadão.

O professor de matemática do colégio da rede pública considera o ensino da educação financeira pessoal bastante relevante para a formação do cidadão brasileiro. Afirma que o cidadão brasileiro não está acostumado a refletir sobre o assunto, e o faz apenas quando precisa de dinheiro para resolver uma dificuldade. Ressalta que os principais responsáveis por promover e atuar diretamente na educação financeira da população são primeiramente os pais e em seguida o Estado e a escola. Em sua opinião, o Estado poderia desenvolver programas de educação financeira pessoal, que não são percebidos hoje na sociedade e que a escola poderia atuar conjuntamente nestes programas. Indica que o início ideal para o ensino da educação financeira pessoal seria no Ensino Fundamental, quando a criança começa a amadurecer, podendo entender melhor seus gastos e suas receitas (mesada), trabalhando o seu comportamento em relação ao dinheiro. Em seguida, o Ensino Médio deve oferecer as ferramentas necessárias para o desenvolvimento do jovem em relação ao tema.

O coordenador do colégio concorda com a professora no que tange a relevância do ensino da educação financeira pessoal e destaca sua utilidade quando se trata das ferramentas que podem auxiliar o aluno em suas dificuldades financeiras. Acredita que o principal responsável por promover e atuar diretamente 
na educação financeira da população é o Estado e considera haver poucas ações na sociedade em relação ao tema. Responde de forma positiva quando se pergunta sobre a importância da escola ser um difusor da educação financeira pessoal, afirmando que comportamentos em relação a dinheiro podem ser melhorados ao se conscientizar os alunos em relação ao tema. Acredita que hoje as pessoas tendem a gastar descontroladamente por conta de maus hábitos. O coordenador considera ainda que o conteúdo de finanças pessoais pode ser trabalhado paulatinamente desde as séries iniciais, pois é neste momento que se começa a orientar a criança com relação ao valor do dinheiro, a poupança e a adquirir consciência da necessidade do consumo postergado para usufruir futuramente. Faz algumas outras considerações, dizendo que considera que esta seja a geração do consumo e que esta geração precisa pensar no futuro, uma vez que a aposentadoria é um dos temas que merece atenção para quem está iniciando sua carreira.

No colégio da rede privada, o professor de matemática entrevistado afirma ser fundamental o ensino da educação financeira pessoal para a formação do cidadão brasileiro, sendo tão importante quanto qualquer outra matéria ou até mais importante. Considera a existência de excelentes profissionais que dedicam grande parte do seu tempo ao trabalho, mas que não dedicam tempo algum para administrar os frutos deste trabalho, o que vê como uma grande contradição. Ressalta que a educação financeira é determinante para o aumento da qualidade de vida das pessoas e para que haja maior produtividade no trabalho, garantindo uma vida financeira estável.

O mesmo professor vê o ensino da educação financeira pessoal como um dos assuntos mais importantes para a formação do aluno. Considera que a maior responsabilidade em educar financeiramente a população é dos pais, que deveriam ensinar através do exemplo, da atribuição de tarefas, ao delegar serviços, da remuneração e da produção, em conjunto com os filhos, da planilhas de gastos, sendo esta uma responsabilidade da família. Acredita que por parte do estado poderia haver políticas públicas que conscientizassem as pessoas e estabelecessem a obrigatoriedade do ensino da educação financeira em sala de aula, no Ensino Fundamental e Médio, não podendo o estado também se eximir desta atribuição. O professor comenta que percebe ações relacionadas ao tema na sociedade e que considera a sociedade extremamente consumista, bombardeada pela mídia e por estratégias de marketing, que se não percebidas podem levar a 
decisões precipitadas e erradas. Considera a existência de muitas pessoas sérias trabalhando o tema, assim como instituições, congressos e na internet também. No entanto, no Brasil as pessoas são quase todas analfabetas financeiramente e muito pouco sobre o tema é divulgado.

O professor argumenta que a escola também tem o papel de educar seus alunos frente ao tema e que o ensino deveria começar no Ensino Fundamental, com pequenas conscientizações, como redução de gastos com água e luz. Aproveita-se também para tratar sobre o gerenciamento de mesada ou semanada e da prestação de contas aos pais. No Ensino Médio, o ensino seria mais contextualizado, utilizando-se de planilhas desenvolvidas no computador e noções sobre outras áreas que envolvem as finanças pessoais. Por fim, considera que o tema deve ser abordado desde o início da vida até o fim dela, pois não se vive sem dinheiro e este cerca quase todas as nossas decisões.

O coordenador do mesmo colégio comenta a relevância do ensino da educação financeira para a formação dos alunos, uma vez que estes estão cada vez mais cedo tendo que lidar com o assunto dinheiro. Muitas vezes são responsáveis por gerenciar seu próprio dinheiro sem ter instrução alguma. Coloca que o colégio possui ações voltadas para a educação financeira pessoal e vê como responsável, além da escola, os pais e o governo. Por fim, o coordenador comenta que percebe a escola como um agente social importante na difusão de informações de finanças pessoais.

Os temas percebidos pelos professores e coordenadores como mais importantes para se trabalhar e que se assemelham com os percebidos pelos estudantes são primeiramente o consumo planejado, pela necessidade de se planejar primeiro, projetar objetivos e depois alcançá-los, valorizando o trabalho e o valor do dinheiro. Em segundo lugar está o e gerenciamento de gastos, pois este assunto pode ajudar a evitar o pagamento de juros e a realização de dívidas, além de ser parte fundamental para o planejamento e a realização de objetivos financeiros. Em terceiro lugar, os professores e coordenadores também concordam que é fundamental que seja passado aos alunos informações sobre investimento, sendo esta também uma forma de se pensar no futuro, de se preparar para a velhice e de permitir uma vida mais próspera. 


\section{CONSIDERAÇÕES FINAIS}

\subsection{Conclusões Principais}

Nesta pesquisa objetivou-se investigar e comparar percepções sobre a relevância da educação financeira pessoal em escolas públicas e privadas do Distrito Federal. O trabalho foi motivado pelas complexas mudanças acontecidas no sistema econômico-social mundial vigente que alterou de forma significante a forma como o dinheiro é administrado. Países desenvolvidos parecem já ter despertado para o tema e tomam medidas para que a formação de seus cidadãos esteja de acordo com novas necessidades. No Brasil, por mais que se perceba esta carência, pouca ou nenhuma ação ocorre de forma efetiva, não havendo participação principalmente do Estado em promover políticas públicas que pudessem alterar a forma de se perceber o tema e a diminuição das desigualdades sociais por meio da educação financeira social, tratada aqui como fundamental para o bem estar da sociedade.

Os dados coletados são de pessoas com um perfil específico para a pesquisa. São todos estudantes da terceira série do Ensino Médio, ideais por já terem cursado quase a totalidade da formação básica do sistema educacional brasileiro. Em sua maioria são estudantes de 17 anos de idade, pertencentes a uma escola públicas e uma privada, em sua maioria homens. Cerca de $40 \%$ destes estudantes são pertencentes a uma família com renda mensal bruta que supera os 20 salários mínimos e em torno de $20 \%$ tem sua renda mensal entre 5 e 10 salários mínimos. Aproximadamente $35 \%$ dos estudantes recebem mesada cujo valor médio é de $R \$ 194,00$ enquanto mais de $10 \%$ deles possui fonte de renda independente da de seus responsáveis, sendo, deste total, $83 \%$ da rede pública, e seu valor médio é de $\mathrm{R} \$ 349,00$.

Dos respondentes dos questionários, 99\% consideram o ensino da educação financeira pessoal "muito importante" ou "importante", enquanto nenhum aluno considerou "sem importância". O tema ganha tamanha relevância após a coleta destes dados, pois demonstram que na percepção dos estudantes de Ensino Médio o tema merece atenção. Mesmo assim, quase $65 \%$ dos alunos afirmam nunca ter tido uma aula que envolvesse qualquer um dos temas de educação 
financeira pessoal e mais de $85 \%$ considera ser a escola o local adequado para que possam adquirir tais conhecimentos. Somam-se a estes dados os comentários coletados de professores e coordenadores pedagógicos, que concordam sobre a importância da educação financeira pessoal para a formação do cidadão brasileiro e sobre o papel fundamental que a escola pode exercer ao ser um difusor destas informações, formando pessoas cada vez mais preparadas para administrar seus recursos financeiros de forma saudável e garantir o bem estar da sociedade como participante deste processo.

Mesmo assim, os dados permitem dizer que alguns comportamentos vistos como adequados são utilizados pela maioria dos alunos, como é o caso da intenção de gerenciar melhor o dinheiro, o que demonstra curiosidade sobre o tema e de se comparar os preços antes de comprar. Estes dois comportamentos são vistos de forma positiva para a pesquisa. Porém, no que cabe ao gerenciamento de gastos, percebe-se uma carência com relação a necessidade e importância de se anotar e controlar gastos pessoais mensais. Em se tratando de comportamentos vistos como inadequados, a maioria dos estudantes diz nunca ou quase nunca realizá-los, o que também é positivo. Os estudantes, também em sua maioria, pensam em ser independente financeiramente dos seus responsáveis o mais rápido possível, o que demonstra urgência no ensino da educação financeira pessoal suficiente para que sejam capazes de administrar suas finanças. Por fim, com relação a comportamentos, 95\% dos estudantes assinalaram que consideram importante ter uma vida financeiramente saudável.

\subsection{Sugestões de Políticas Públicas}

Após serem entendidas tais necessidades, é conveniente que se estruturem ações que visem corrigir tal realidade. Para a escola, é possível que algumas ações sejam desenvolvidas a fim de suprir tal lacuna percebida por alunos e professores. Num primeiro momento, pode-se pensar como solução para a instituição de ensino a realização de parcerias com empresas especializadas no ensino da alfabetização financeira pessoal, a fim de que neste primeiro momento se consiga alfabetizar financeiramente os estudantes que estão próximos de concluir o ensino básico. 
Em seguida, pode-se estruturar melhor a escola, a fim de que possa, por si só, formar seus alunos em relação ao tema. Pode-se pensar na formação de professores de diversas áreas que poderiam trabalhar o assunto de forma diferenciada, interligada e que gere no aluno a consciência de que o tema está presente em várias decisões da sua vida. Esta estruturação implicaria também na determinação de aulas para se tratar sobre o tema, com os próprios professores ou com profissionais da área.

Estando a escola preparada em termos de estrutura e horários, pode-se oferecer, então, de forma mais abrangente, o ensino da educação financeira pessoal, permeando toda a formação básica, estabelecendo-se, com a ajuda de especialistas, o momento ideal para se trabalhar cada assunto, dentro e fora de sala de aula, objetivando o incentivo a comportamentos que farão diferença na vida adulta do indivíduo e certamente também nas próximas gerações, que neste ponto, serão educadas de forma diferenciada principalmente pelos pais e também pela escola.

Evidentemente, em se tratando de escola particular, percebe-se uma diferença em relação ao tratamento das mesmas soluções pela escola pública. E não somente isto, pois que algumas sugestões de políticas públicas afetam todo o sistema de ensino e pode-se pensar em algumas medidas que poderiam impulsionar o desenvolvimento do tema e acabar com a falha existente percebida.

Primeiramente, muitas destas sugestões somente serão possíveis de se colocar em prática no momento em que forem percebidas como importantes também para os gestores públicos. A alteração do currículo e a inserção de conteúdos de educação financeira pessoal na formação básica do cidadão é extremamente necessária, sendo ponto fundamental para a realização de várias ações voltadas para solucionar necessidades sobre o tema.

Faz-se necessário uma mudança de cultura. Lança-se um novo paradigma, criado pela necessidade em se obter informações de educação financeira pessoal que possam beneficiar a sociedade e em especial os indivíduos, tomando decisões em família, sabendo ser críticos com relação a oferta de produtos e serviços, principalmente com relação a serviços financeiros, sendo mais produtivos em suas empresas e com maior qualidade de vida gerada pela educação. 


\subsection{Sugestões de Novas Pesquisas}

Sendo assim, os próximos passos para que este cenário desejado seja efetivamente colocado em prática, algumas pesquisas são necessárias. Um ponto interessante de se averiguar é com relação a alguns tópicos sobre educação financeira pessoal mais específicos, principalmente investimentos, bolsa de valores e gerenciamento de gastos, que se caracterizam por apresentarem maior carência de aprendizado.

Outra pesquisa bastante interessante seria para verificar as percepções de outros públicos a fim de se averiguar outras demandas por educação financeira pessoal que possam existir. Dentro de outros públicos também pode-se pensar em comparar percepções de pais e responsáveis a respeito do tema, considerando estes parte da sociedade que tem voz ativa, vota e exige os direitos dos seus filhos. Pode-se considerar também pessoas recém empregadas no primeiro emprego, a fim de entender suas maiores dificuldades em gerir seus recursos financeiros.

Seria interessante e necessária uma pesquisa mais profunda voltada para a área educacional, onde o resultado desta seria uma solução de inserção da educação financeira pessoal durante a formação básica do cidadão. Pode-se trabalhar desde as séries iniciais, onde a educação financeira poderia ser ensinada por meio do exemplo e da criação de contextos para que o aluno adquira comportamentos importantes para a gestão de sua vida financeira, até o Ensino Médio, momento em que poderiam ser passadas informações que visariam auxiliar o estudante na manutenção e melhoria dos comportamentos adquiridos. Os conteúdos podem ser tratados de forma transversal, ou seja, envolvendo toda a atmosfera escolar. Parte deste estudo também se dedicaria à forma como se pretende que as crianças percebam a educação financeira, sendo divulgada de forma desafiadora, necessária e interessante, não sendo percebida como mais uma disciplina que o aluno será obrigado a estudar para passar de ano sem que necessite absorver o conteúdo.

Por último, sugere-se que seja realizada uma pesquisa mais abrangente, que colete informações sobre os impactos gerados pela educação financeira pessoal na vida adulta do cidadão, comparando estilos de vida, preocupações e qualidade de vida destes indivíduos com os indivíduos que não tiveram acesso a tais informações para averiguar se existe diferença de comportamentos, hábitos e 
costumes, que no decorrer dos anos tenham gerado alguma diferença muito expressiva por conta do ensino de finanças pessoais. Evidentemente esta pesquisa só poderia ser realizada a partir do momento em que se desse início o processo de mudança que vise a difusão de tais informações.

Conclui-se que a educação financeira pessoal é um tema de bastante relevância tanto para alunos da terceira série do Ensino Médio quanto para professores e coordenadores de colégios públicos e privados do Distrito Federal. Após ter ciência destes dados, o importante aproveitá-los para que haja uma cobrança por soluções por parte dos responsáveis visando a diminuição da lacuna existente entre as demandas dos indivíduos e a oferta fomentada pelo Estado. Cabe neste momento salientar o grande interesse gerado pela pesquisa por parte de todos os envolvidos, incluindo-se professores, coordenadores pedagógicos e alunos. Por conta deste interesse, todos os objetivos da pesquisa foram atingidos e pôde-se entender melhor outras percepções sobre o tema, mesmo havendo limitação por esta ser uma das primeiras pesquisas sobre o tema no país. 


\section{REFERÊNCIAS}

BITENCOURT, C. P. V. Finanças pessoais vs finanças empresariais. 2004. 85 p. Dissertação (Mestrado em Controladoria) - Faculdade de Ciências Econômicas, Universidade Federal do Rio Grande do Sul, 2004.

BOLSA DE VALORES DO ESTADO DE SÃO PAULO - BOVESPA. Disponível em: $<$ HTTP://www.bovespa.com.br/> Acesso em 24 de abril de 2009.

BONALDI, E. V. Bovespa e educação financeira: a hegemonia neoliberal e a gestão das finanças pessoais no universo das classes médias brasileiras. São Paulo: USP, 2008.

BRASIL. Banco Central do Brasil. Disponível em: <HTTP://www.bcb.com.br/> Acesso em 24 de abril de 2009.

BRIGHAM, E. F; HOUSTON, J. F. Fundamentos da Moderna Administração Financeira. Rio de Janeiro: Campus, 1999.

CERBASI, G. Casais inteligentes enriquecem juntos. São Paulo: Gente, 2004.

CHERRY, R. T. Introdução à Administração Financeira. São Paulo: Atlas, 1976.

COOPER, D. R; SCHINDLER, P. S. Métodos de pesquisa em administração. Porto Alegre: Bookman, 2003.

DANTE, L. R. Matemática: Contexto e Aplicações. São Paulo: Ática, 2001.

GIL, A. C. Métodos e Técnicas de Pesquisa Social. São Paulo: Atlas, 1999.

GITMAN, L. J. Princípios de administração financeira. Porto Alegre: Bookman, 2001.

HALFELD, M. Investimentos: Como administrar melhor o seu dinheiro. São Paulo: Fundamento Educacional, 2004.

IEZZI, G. et al. Matemática: Volume Único. São Paulo: Atual, 1997.

INSTITUTO DE EDUCAÇÃO IVOTI. Disponível em: <HTTP://www.iei.org.br/>. Acesso em 28 de abril de 2009.

MARTINS, J. P. Educação financeira ao alcance de todos. São Paulo: Fundamento, 2004.

MATTA, R. O. B. Oferta e demanda de informação financeira pessoal: o Programa de Educação Financeira do Banco Central do Brasil e os universitários do Distrito Federal. 2007. 214 p. Dissertação (Mestrado em Ciência da Informação) Faculdade de Economia, Administração, Contabilidade e Ciência da Informação, Universidade de Brasília, Brasília, 2007. 
MATTA, R.; AMARAL, S. Oferta e demanda de informação financeira pessoal: o Programa de Educação Financeira do Banco Central do Brasil e os universitários do Distrito Federal. São Paulo: USP, 2008.

SAITTO, A. T.; SAVOIA, J. R. F.; PETRONI, L. M. A educação financeira no Brasil sob a ótica da Organização de Cooperação de Desenvolvimento Econômico (OCDE). São Paulo: USP, 2006.

SAVOIA, J. R. F.; SAITO, A. T.; SANTANA, F. A. Paradigmas da educação financeira no Brasil. Rio de Janeiro: RAP, 2007.

SERASA. Disponível em: <HTTP://www.serasa.com.br/guia/conteudo.htm> Acesso em 24 de abril de 2009.

VERGARA, S. C. Projetos e Relatórios de Pesquisa em Administração. São Paulo: Atlas, 2009. 


\title{
APÊNDICES
}

\section{Apêndice A: Questionário}

\author{
$\varnothing$ \\ Universidade de Brasília \\ DEPARTAMENTO DE ADMINISTRAÇÃO - TRABALHO DE CONCLUSÃO DE CURSO
}

\section{Questionário}

\section{Pesquisa sobre demandas de educação financeira pessoal dos estudantes do Ensino Médio de escolas públicas e privadas do Distrito Federal.}

Obrigado pela sua participação nesta pesquisa que objetiva descobrir a demanda (uso e necessidade) de informação sobre educação financeira pessoal por parte dos estudantes secundaristas do Distrito Federal. Trata-se de um trabalho de conclusão de curso superior em Administração desenvolvido na Universidade de Brasília.

O preenchimento das informações é opcional, mas gostaria de sua colaboração para a pesquisa. Todos os dados coletados serão utilizados única e exclusivamente para a pesquisa em questão e trabalhados de forma a proteger o seu anonimato.
1) Sexo
( ) Masculino
( ) Feminino
2) Idade anos
3) Qual melhor alternativa descreve a renda mensal de sua família:
( ) $R \$ 465,00$ ou menos
( ) $R \$ 465,00$ a $R \$ 1.395,00$
( ) $R \$ 1.395,00$ a $R \$ 2.325,00$
( ) $R \$ 2.325,00$ a $R \$ 4.650,00$
( ) $R \$ 4.650,00$ a $R \$ 9.300,00$
( ) mais que $R \$ 9.300,00$
4) Você recebe mesada?
( ) Sim. Valor: $\mathrm{R} \$$
( ) Não
5) Possui alguma fonte de renda independente da de seus responsáveis? (Ex. Trabalho, estágio)
( ) Sim. Valor: $\mathrm{R} \$$
( ) Não

Entende-se Educação Financeira Pessoal como o conjunto de conhecimentos que auxilia a pessoa a gerenciar melhor sua disponibilidade financeira. São informações que educam você a administrar corretamente o seu dinheiro, a gastar e utilizar créditos disponíveis, poupar e investir, de modo que você tenha uma vida financeiramente saudável.

6) Em sua opinião, obter informações voltadas à educação financeira pessoal é: 

( ) muito importante
( ) importante
( ) pouco importante
( ) sem importância

7) Dos itens abaixo, escolha 5 que você tem interesse em obter mais informações e enumere-os de 1 a 5 , sendo 1 o item que você tem mais interesse e 5 o item que você tem menos interesse:
( ) Uso do cartão de crédito
( ) Empréstimos pessoais
( ) Poupança
( ) Financiamentos
( ) Consumo planejado
( ) Bolsa de Valores
( ) Juros
( ) Gerenciamento de gastos
( ) Aposentadoria
( ) Outros assuntos. Qual (is)?
( ) Não tenho nenhum interesse

8) Dos itens abaixo, marque com um " $x$ " o(s) que você considera já possuir informações suficientes para tomar decisões a respeito do assunto:
( ) Uso do cartão de crédito
( ) Empréstimos pessoais
( ) Poupança
( ) Financiamentos
( ) Consumo planejado
( ) Bolsa de Valores
( ) Juros
( ) Gerenciamento de gastos
( ) Aposentadoria

( ) Outros assuntos. Qual (is)?

( ) Não possuo nenhuma informação.

9) Você já teve alguma aula cujo conteúdo ministrado estava relacionado à educação financeira pessoal?
( ) $\operatorname{Sim}$
( ) Não

10) Em sua opinião, a educação financeira pessoal deveria ser ensinada na escola?
( ) Sim
( ) Não.

11) Conforme o seu comportamento e seu modo de pensar. VOCÊ:

\begin{tabular}{|l|l|l|l|l|}
\hline & Nunca & $\begin{array}{c}\text { Quase } \\
\text { nunca }\end{array}$ & $\begin{array}{c}\text { Quase } \\
\text { sempre }\end{array}$ & Sempre \\
\hline a) Preocupa-se em gerenciar melhor o seu dinheiro & & & & \\
\hline $\begin{array}{l}\text { b) Identifica a existência de juros ao comprar um } \\
\text { produto à crédito (ex.: juros embutidos) }\end{array}$ & & & & \\
\hline $\begin{array}{l}\text { c) Anota e controla os seus gastos pessoais mensais } \\
\text { (ex.: planilha de receitas e despesas, caderno de } \\
\text { anotações, etc.) }\end{array}$ & & & & \\
\hline $\begin{array}{l}\text { d) Está satisfeito com o sistema de controle de suas } \\
\text { finanças }\end{array}$ & & & & \\
\hline $\begin{array}{l}\text { e) Estabelece metas financeiras que influenciam na } \\
\text { administração do seu dinheiro (ex.: Poupar uma } \\
\text { quantia no ano) }\end{array}$ & & & & \\
\hline f) Poupa visando a compra de um produto mais caro & & & & \\
\hline $\begin{array}{l}\text { g) Poupa mensalmente sem ter necessariamente a } \\
\text { intenção de consumir algo com o dinheiro poupado }\end{array}$ & & & & \\
\hline h) Pensa em investir o seu dinheiro & & & & \\
\hline i) Compara preços ao fazer compras & & & & \\
\hline
\end{tabular}


j) Compra por impulso

k) Paga suas contas em atraso

I) Seus gastos mensais ultrapassam o valor recebido mensalmente

m) Não tem limite de gastos mensais, compra tudo o que quer e quando quer

n) Prefere comprar um produto financiado a juntar dinheiro para comprá-lo a vista

o) Pensa em ser independente financeiramente dos seus responsáveis o mais rápido possível

p) Considera importante ter uma vida financeira saudável 


\title{
Apêndice B: Roteiro de Entrevista
}

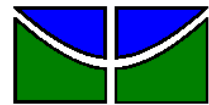 \\ Universidade de Brasília \\ DEPARTAMENTO DE ADMINISTRAÇÃO - TRABALHO DE CONCLUSÃO DE CURSO
}

\section{ROTEIRO DE ENTREVISTA}

Nome da Escola:

Cargo do entrevistado:

Entende-se Educação Financeira Pessoal como o conjunto de conhecimentos que auxilia a pessoa a gerenciar melhor sua disponibilidade financeira. São informações que educam você a administrar corretamente o seu dinheiro, a gastar e utilizar créditos disponíveis, poupar e investir, de modo que você tenha uma vida financeiramente saudável.

1. Você considera relevante o ensino da educação financeira pessoal para a formação do cidadão brasileiro? Comente.

2. Em sua opinião, quem deveria ser o responsável por promover e atuar diretamente na educação financeira da população?

3. Você percebe alguma ação de educação financeira hoje na sociedade?

4. Você acha que a escola poderia fomentar a difusão de informações de educação financeira pessoal para a formação de adultos mais preparados para tomar decisões financeiras?

5. O Ensino Médio seria o momento adequado para o ensino de educação financeira pessoal?

6. Dos assuntos abaixo, quais você considera mais relevantes para a formação de um adulto capaz de administrar sua vida financeira de forma saudável? Enumere em ordem de importância de 1 a 5 , sendo 1 o mais relevante e 5 o menos relevante.
( ) Uso do cartão de crédito
( ) Empréstimos pessoais
( ) Poupança
( ) Financiamentos
( ) Consumo planejado
( ) Bolsa de Valores
( ) Juros
( ) Gerenciamento de gastos
( ) Aposentadoria
( ) Outros assuntos. Qual (is)?
( ) Não tenho nenhum interesse 